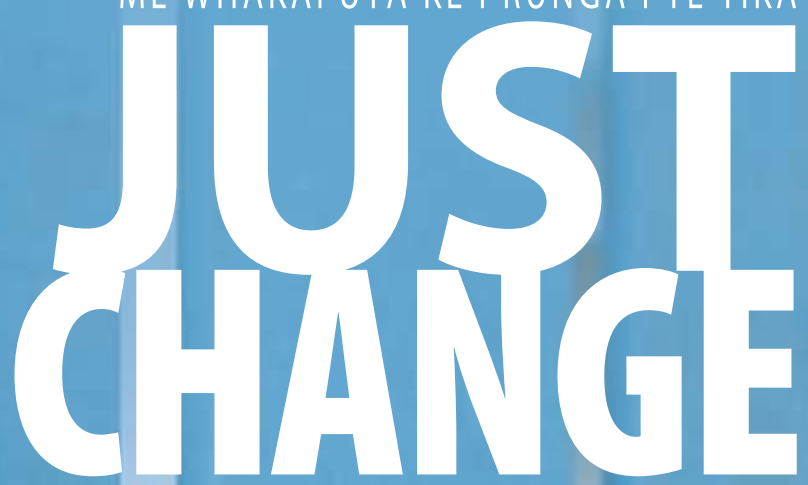

CRITICAL THINKING ON GLOBAL ISSUES He whakaaro kaikini mō ngā take o te ao

\section{Access to}

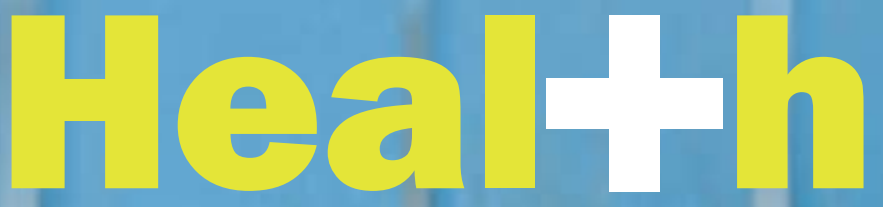

\section{Te Wātea o Te Haucra}

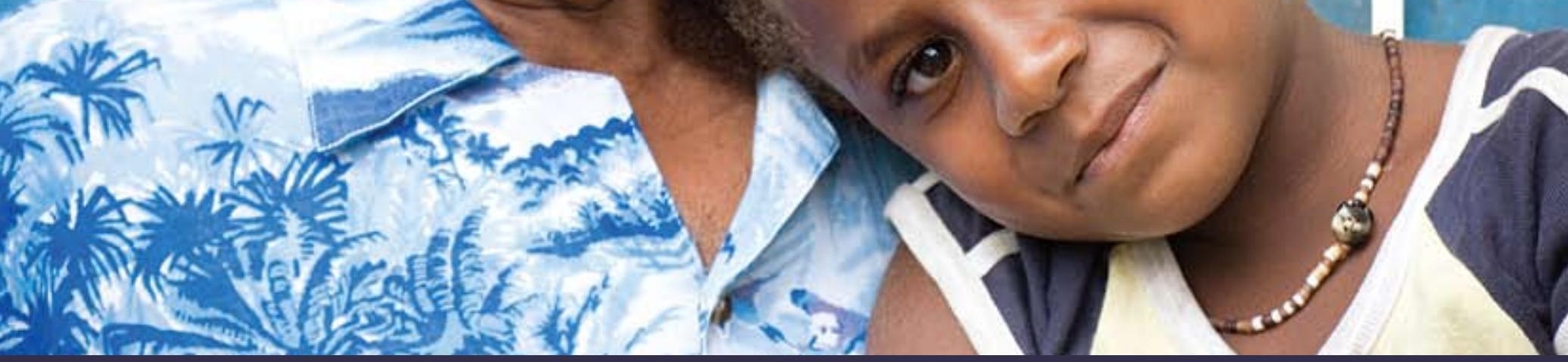

THE AIDS FIXATION

Does the world really need more HIV and AIDS funding?
MEDICAL TOURISM

What does this affluent new industry mean for the world's majority?

KA WHAKAPUTA KÉ KIA TIKA AI TE AO

$\begin{array}{lllllllllllllllllll}\text { C } & H & A & N & G & E & F & \text { O } & \text { R } & \text { A } & \text { J } & \text { U } & \text { S } & \text { T } & \text { W } & \text { O } & R & \text { L } & \text { D }\end{array}$

dev-zone 
CHSTE

Just Change is produced by Dev-Zone (www.dev-zone. org), a programme of the Development Resource Centre (DRC) - a not-for-profit, non-governmental organisation governed by a charitable trust. We are core funded by NZAID Nga Hoe Tuputupu-mai-tawhiti, New Zealand's international aid and development agency. Funding for the printing of Just Change comes from independent sources.

The DRC's two programmes are Dev-Zone (www. dev-zone.org), a resource centre on international development and global issues for the developmen and human rights sector, as well as tertiary students and the general public, and the Global Education

Centre (www.globaled.org.nz), which provides training and resources on global education to the formal and non-formal education sectors.

The motivation for Just Change falls under Dev-

Zone's mandate to inform and educate people to take action to create a just world. Grounded in Aotearoa New Zealand and the Pacific, but with a global reach, Just Change prioritises a holistic, sustainable approach to development; a call for the development community and the general public to take action; and an overall aim of ensuring that the voices - and the issues - of those who are most vulnerable are heard. Just Change is a product of, by, and for those who are invested in sustainable development, social justice, and human rights. The magazine is published every four months - each issue is based on a different global concern. Writers are not journalists; they are either those working in development or students/teachers of development studies and related programmes. Articles and other contributions are based on academic research and/or development work in the field.

To subscribe to Just Change, please email info@devzone.org or contact us at the address below.

Published by Dev-Zone, Level 2 James Smith Building 55 Cuba Street, P.O. Box 12440, Wellington, Aotearoa New Zealand.

Tel: + 6444729549

Fax: + 6444969599

Email: info@dev-zone.org

URL: www.dev-zone.org

Editors: Alice Beban and Elena Wrelton, Dev-Zone Printer: The Print Room

Design: Miranda Lees, Development Resource Centre

Te Reo: Piripi Walker

Proofreading: Beth Thomas

Cover image: Henry Heeu with his granddaughter following sight-restoring surgery performed by a Fred Hollows Foundation NZ surgical team during an outreach to Levuka in Fiji. Photo: Kristian Frires.

This publication may be copied or downloaded from our website at www.dev-zone.org/justchange and distributed for educational and information purposes on the condition that the source is acknowledged. No part of this publication may be reproduced in any form for commercial purposes without the prior permission of Dev-Zone. The views expressed in this magazine are not necessarily the views of Dev-Zone.

Copyright $\odot$ Dev-Zone 2009

ISSN: 1176-8185

\section{Guest Dditorial}

He Whakaaro nā te Ėtita Tāpae Wakaaro
Health is at the heart of human development. Yet the following story from LYNNE PERE, a Māori Health Postdoctoral Research Fellow at Victoria University of Wellington (contact: lynne. pere@vuw.ac.nz), reminds us that access to health is not a simple issue; having the right legislation in place does not ensure that everyone will benefit. Barriers to healthcare, large and small, cultural or structural affect many of the world's people. This issue of Just Change highlights these barriers and the inspiring ways people, families and governments are working to bring them down and restore life to our health system.

\section{ACCESS TO HEALTH: THE NEED FOR CHANGE}

in n March 2008 the most important person in my world ended his life. My husband was my love, my soul mate; my life. On that day my world changed forever.

In the ensuing days and months, as shock was replaced with throbbing pain, I began to search for sense. Revisiting every step exposed many questionable decisions, not all of them my husband's. Through my search, I have begun to understand the need for change in our health system.

Ironically perhaps, I am a Māori health researcher; my current work focuses on the importance of sharing the meanings behind thoughts and ideas of indigenous peoples with experiences of mental illness in order to improve mental health recovery. Commonsense dictates that to disregard research findings, to not translate them into practice, is futile. Yet my search suggests that research evidence is often ignored.

Key principles of good mental health practice based in evidence and entrenched in legislation, such as the Code of Health and Disability Services Consumers' Rights 1996, were remiss in the care of my husband. Information about known side-effects of deepening depression and suicidal thoughts in early stages of his prescribed medication was withheld from him, a follow-up appointment was not made for him despite this, and his psychiatric assessment was not shared with key health professionals involved in his care. Other clear guidelines in working with Māori were completely ignored. Being assessed alone, by non-Māori, is but one example. All these actions collectively played a part in determining the outcome.
Ample evidence supports the need to recognise cultural fit between clinician and client, as well as the need for an unobstructed flow of information between clinicians, providers, clients and whānau. Accumulating research also shows the absolute importance of whānau in Māori mental health.

However, the importance and significance of whānau, hapū and Iwi ties, and the contribution those ties make to well-being, emphasised in the Mental Health (Compulsory Assessment and Treatment) Act 1992, were empty rhetoric in our case. I believe that had any of the numerous health professionals involved in my husband's treatment in the weeks prior to his death asked me - the whānau member most evidently and directly concerned with the oversight of his care and welfare (to use the Act's terminology) - about his mental state, I could have categorically told them he was suicidal. As it was, each of them assessed him to the contrary without any consultation with whānau, and all were shocked at the outcome. I was not. I was devastated.

In Māori mental health, it is imperative that the real involvement of whannau, inclusive of the person with the experience, changes from an idealised goal to actuality. Māori do not function as individuals but as members of whānau, hapu and Iwi. When one presents as mentally unwell, this represents unwellness in the whannau, and health services need to be targeted and delivered accordingly. To focus on my husband as an individual without consideration of him as one of our whānau was careless. He needed us and we needed help. This collective approach to health is the fundamental underlying principle of our government's Māori health policy: whānau ora.

If we are serious about improving access to healthcare for Māori, then we need to change. Health is about sustaining connections and relationships. Ill-health is about losing them. Just as effective relationships between health professionals and services are essential for effective mental health care, so are relationships with and within whānau.

To not change could be fatal.

Coming up: The next issue of Just Change, due out in June 2009, will look at 'What is Poverty?' For further information please contact justchange@dev-zone.org 


\section{CWSTE}

Access to

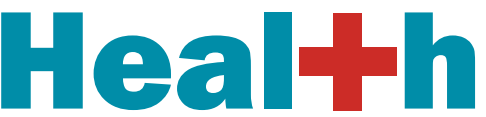

Te Wātea o Te Hauora
Photo: $\odot 2007$ Bonnie Gillespie, Courtesy of Photoshare.

Health hurdles

Finance, geography and many other hurdles need to be overcome before access to health care for the majority becomes reality.

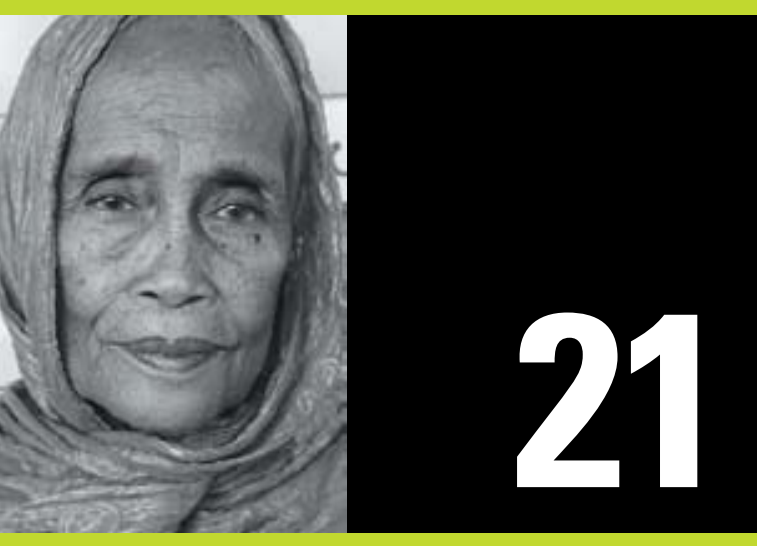

Photo: C.Henderson.

\section{Sipakatau: Holistic healthcare}

Traditional and conventional maternal healthcare are brought together in Indonesia.

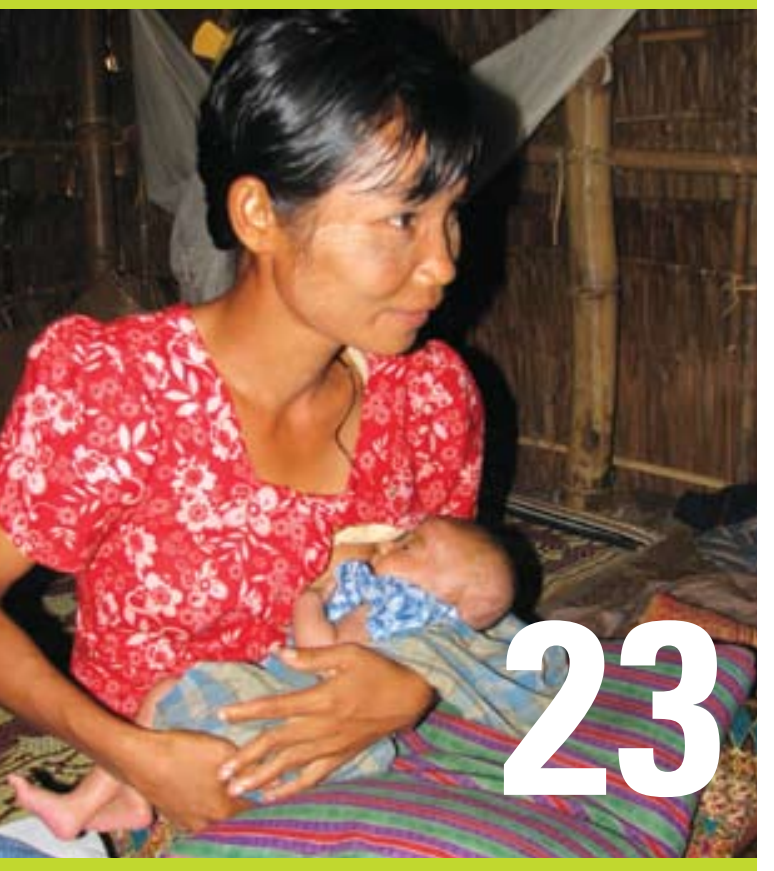

Photo: Nina Berry.

\section{Development for babies!}

Why does breastfeeding receive so little funding and consideration in development?
2. Guest Editorial/He Whakaaro nā te Ėtita Tāpae Wakaaro Lynne Pere

4. Access to health

Overview of the barriers preventing people from achieving their best possible health

FEATURES/NGĀ TUHINGA

6. Health hurdles: Ensuring access to health for the majority Maria $A u$ and David Peters

7. Public vs private: Developing accessible health systems Tim Anderson

8. Does the world really need more HIV and AIDS funding? Jo Spratt

10. HIV and AIDS medicine: Trade law, diplomatic pressure, and the future supply of generics

Thomas Owen

11. Trade and access to medicines in Fiji and the Pacific Sarah Meads

FOCUS ON THE PACIFIC/KA AROTAHI KI TE MOANA-NUI-A-KIWA

12. Falling short: Health and the MDGs in the Pacific Manoranjan Mohanty

13. Mãori and the cancer journey The Mãori Experiences of Cancer Research Team

14. OPINION Access in Aotearoa Dorothy Kennach, Flora Toma, Somali Council

16. Championing mental health in the Pacific Margaret Leniston

17. Money isn't everything: Health aid effectiveness takes time Carmel Williams and Garry Brian

18. Building a healthy future for women Melanie Heaphy, NZAID

19. Beyond the classroom: Health workforce development in the Pacific Rènée du Toit and John Szetu

20. The need for young people's voices in the fight against HIV and AIDS David Ephraim

ARTICLES/TUHITUHINGA

21. Sipakatau: A holistic approach to maternal healthcare Chris Henderson

22. Climate change and children's health Sheridan Bartlett

23. Development for babies! Bindi Borg

24. Carving out a space: Access to healthcare and aid for Somali and Sudanese refugees Karly Christ

25. Medical tourism: Subsidising healthcare for majority world countries Nikhila M. Vijay and Nirmal Joy, KABANI

26. A case of neglect? African sleeping sickness in Uganda Jessica Lemieux

COMMUNITY/TE HAPORI

27. News from the DRC, Take Action, Letters

28. Resources from the DRC

References used in the writing of these articles are available on www.dev-zone.org. 


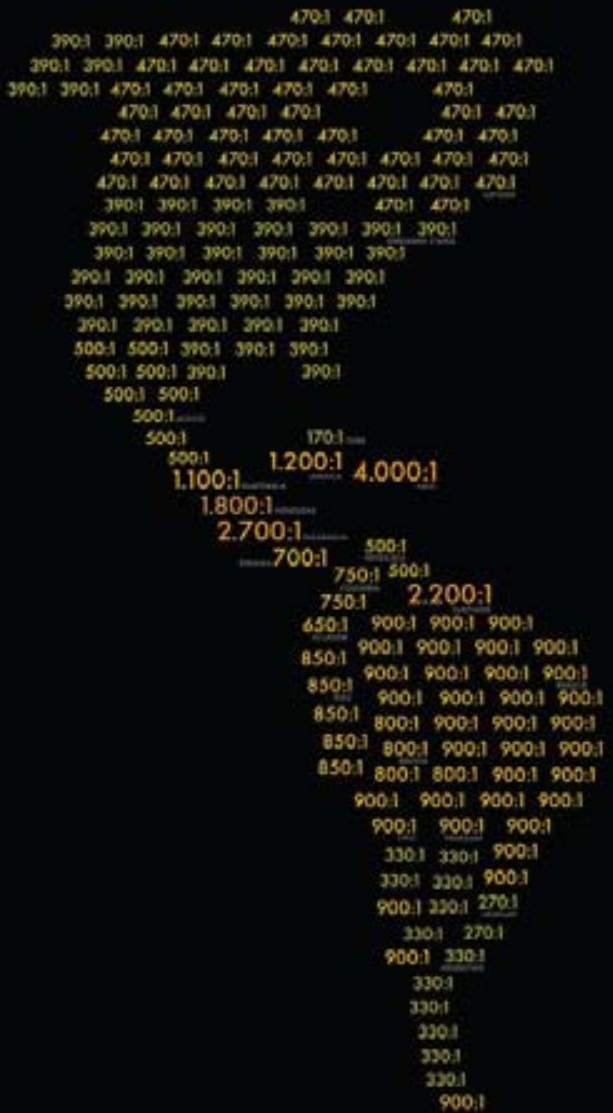
22012301

23012301 2301 2301 2301 2304 2301

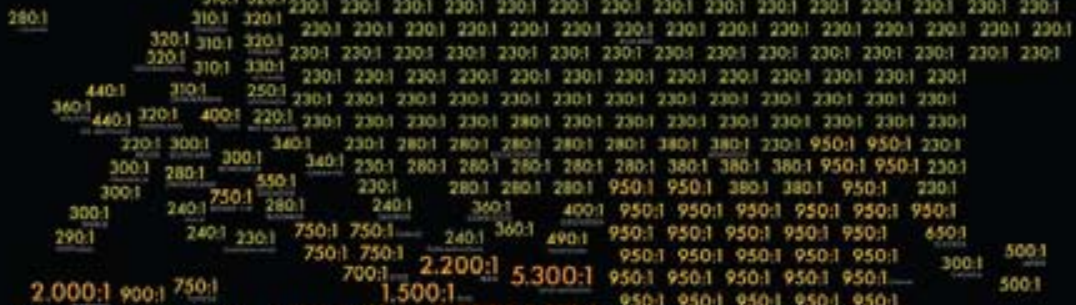

2001

\section{Access to health}

\section{'The opportunity or right to receive health care'}

\section{(MedicineNet.com)}

$\mathrm{H}$ ealth is essential, not only to our personal well-being; it is essential to every part of our lives. It impacts on a person's ability to work, to participate in their community, to look after their family, all the essential elements of maintaining a quality of life. It is a basic human right, affirmed in Article 25 of the Universal Declaration of Human Rights and the Declaration of Alma Ata (see Glossary).

Ensuring access to health is complicated, affected by a multitude of interlinking factors including poverty, culture, disability, government policy and capacity, trade rules, gender, age and inequality.

\section{POVERTY = ILL HEALTH = POVERTY}

Poverty and health are inextricably linked. Lack of health can be a cause of poverty and vice versa.

The World Health Organisation (WHO) estimates that $45 \%$ of the diseases affecting those in the poorest countries are those associated with poverty. When asked, the poor themselves mention ill health more than loss of employment as a creator of poverty.

Poverty limits a person's access to the conditions for good health, including their access to:

- clean water and sanitation facilities

- a healthy environment

- good nutrition

- education.

Increasingly the impacts of climate change will be felt by the poorest, and the risk their health will suffer as a result is high.

\section{MALNUTRITION AND OBESITY:}

\section{A PARADOX OF POVERTY}

While undernutrition and starvation remain serious issues in many countries, and are shown to be leading risk factors in child deaths worldwide, the obesity epidemic is also affecting both the minority and majority world. Where being overweight may once have been a sign of prosperity, the ability to eat rich and expensive foods, it is now, increasingly, a condition of poverty. Caused by a mixture of easy access to fast foods; high in fat and salt, and socio-economic conditions that prevent people from being able to afford healthy alternatives it is having serious health implications across the world. 
IT'S WHO YOU ARE NOT WHAT YOU ARE

Access to health is further limited for people in certain groups. Already disadvantaged groups are limited by cultural issues, their legal or social status:

- women

- disabled

- elderly

- refugees and asylum seekers

- indigenous people

- people in conflict areas.

WHERE IS THE MONEY (NOT) COMING FROM? A government's ability to provide healthcare for its population is dependant on their capacity to provide services and their ideological commitment to providing them. Their financial capacity has been affected by:

- high cost of debt repayments

- structural adjustment packages that demand they reduce spending on public services

- high cost of medicines and equipment.

As a result, a variety of financing mechanisms have developed, with varying implications for increasing access to healthcare.

\section{PAYING FOR MEDICAL MIRACLES}

There has been much debate about how health research and development is funded. According to the Global Forum for Health Research, $97 \%$ of health research is done in minority world countries. This, coupled with the strong influence of private pharmaceutical companies, results in medical research focused on minority world diseases and solutions that will quickly earn companies a profit before the end of the patent is reached. The interests of minority world pharmaceutical developers have been further protected by trade laws such as TRIPS that have protected the patents of drug companies and prevent access to life-saving medicines in the majority world.

\section{YOU JUST CAN'T GET THE STAF}

One factor affecting both the majority and minority world is a shortage of health workers. Doctor to population ratios vary dramatically both between and within countries. Rural or poorer areas tend to have less appeal to doctors wherever they work in the world. The situation in the majority world is compounded by the lack of educational opportunities to train health workers and the recruitment of medical staff to fill the shortages that exist in the hospitals of minority world countries. To give just two examples, it is estimated that in 1999 Ghana lost more nurses to migration than it trained and in the $1990 \mathrm{~s}$ two thirds of Jamaica's nurses left the country permanently. Tempted by higher wages, the remittances these workers earn contribute to the general well-being of their families but reduce their countries' capacity to provide healthcare for their own populations.
PRINCIPAL FINANCING METHODS

Tax-Based

Private Insurance

Funded from government revenue derived from general tax or sector specific taxes.

People pay a premium to cover their health costs. It is usually voluntary and funds are normally held by private company. High risk groups such as those with low socioeconomic status pay more than low risk groups.

Social Insurance Funding

Employees and employer pay a percentage of salary into a communal fund that is independent of government. Those less able to pay are subsidised by those earning more.

User Fees

Patients pay directly for the services they use. It is the most common way to pay for private health services in majority world countries.

Community-Based Health Works in a similar way to social insurance funding but is not normally mandatory or linked to Insurance

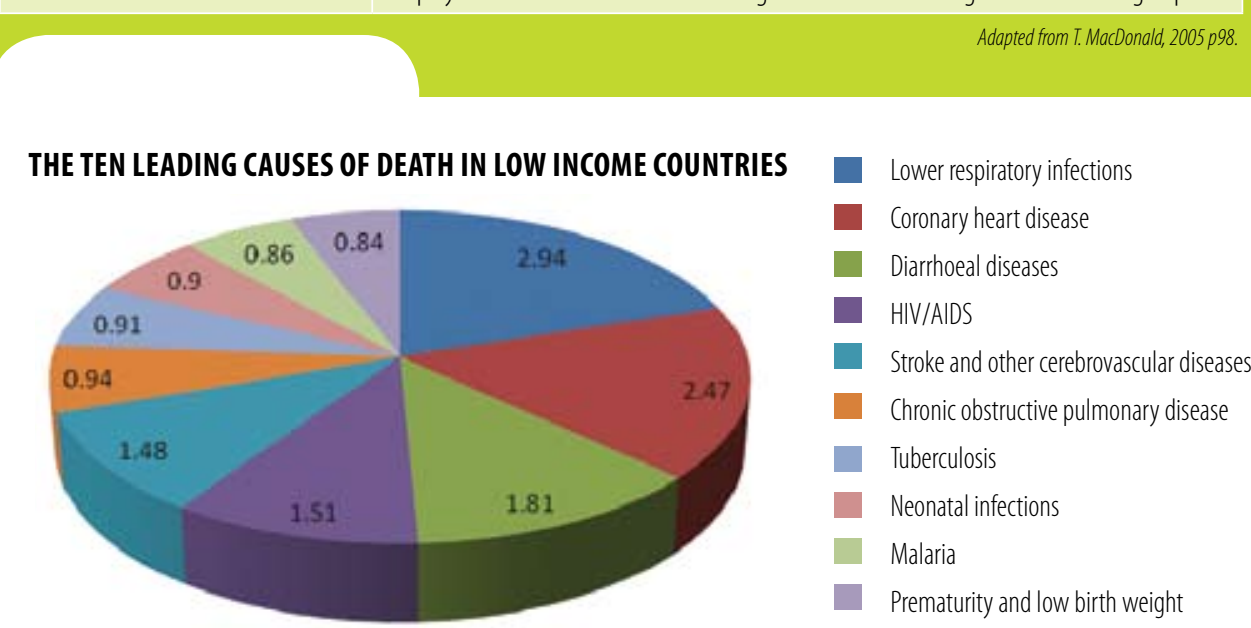

PER CAPITA TOTAL EXPENDITURE ON HEALTH AT AVERAGE EXCHANGE RATE (NZ\$)

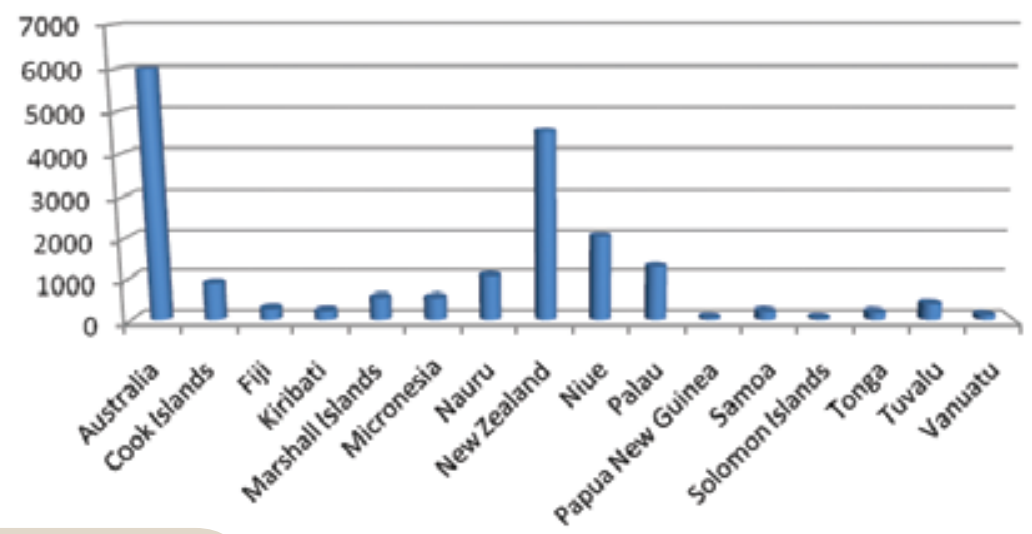

\section{Glossary}

Declaration of Alma Ata: Adopted at the International Conference on Primary Health Care held in Alma Ata, Kazakhstan in 1978, this was the first declaration on primary healthcare and called for urgent and effective action by governments and civil society. It reaffirmed health as a human right and a socio-economic issue, closely related to issues of equity.

Public health: The approach to medicine that is concerned with the health of the community as a whole. Public health is community health. It has been said that: 'Health care is vital to all of us some of the time, but public health is vital to all of us all of the time'. (Medicinenet.com)

TRIPS (Agreement on Trade Related Aspects of Intellectual Property Rights): An international agreement first negotiated in 1994 and administered by the World Trade Organisation. It sets minimum standards for intellectual property regulation by countries.

Doha Declaration on the TRIPS Agreement and Public Health:A declaration issued in 2001 by the WTO in response to the concerns of majority world countries that TRIPS was limiting their access to essential medicines. It allows countries to issue compulsory licenses on patents for medicines. An amendment to the TRIPS agreement was put forward in 2005 to create a mechanism for countries to export generic medicines to countries without the ability to produce these medicines themselves. The amendment is currently not ratified by enough countries to make it legally binding. For explanations of other terms see our glossary www.dev-zone.org/devguide 


\section{Health Hurdles}

\section{Ensuring access to health for the majority}

Introducing many of the factors that limit people's access to healthcare, MARIA AU and DAVID PETERS consider the impact that finance, geography, availability and acceptability of services have in accessing healthcare in the majority world.

\section{Access to Health - the timely use of health} services according to people's needs

A round the world, poor people tend to have less access to health services. This disparity is not new and the barriers that create it are common. The complex relationship between poverty and access to health services is often part of a vicious cycle where poverty leads to ill health, and ill health deepens poverty.

Wide inequities in health services exist across different regions. South Asian countries tend to have the most unequal use of health services across different types of health provision, whereas Europe-Central Asian low and middle income countries (LMICs) tend to be more equal. Just as shortfalls in coverage vary across regions and countries, they vary within countries, with the poor and other deprived groups usually lagging behind. LMICs have $90 \%$ of the global burden of disease but account for only $12 \%$ of global spending on health. As a result, the poorer the country, the greater portion of health spending is paid out-of-pocket by families. This way of paying often creates a barrier to care, and places people at financial risk when they become ill. For nearly all LMICs, public spending on health disproportionately benefits wealthier citizens, so that total health spending is often highly inequitable.

Affordability is one of the most important determinants of access by the poor. Besides the direct cost of treatment, there are also indirect costs that deter the poor from seeking treatment. The time lost that could be spent earning money, transportation costs, and expenses on food and lodging when accessing healthcare all create barriers. The economic consequences of these direct and indirect costs include spending high proportions of household finances (catastrophic spending), borrowing money, or the selling of assets (distress financing), which can push people deeper into poverty.

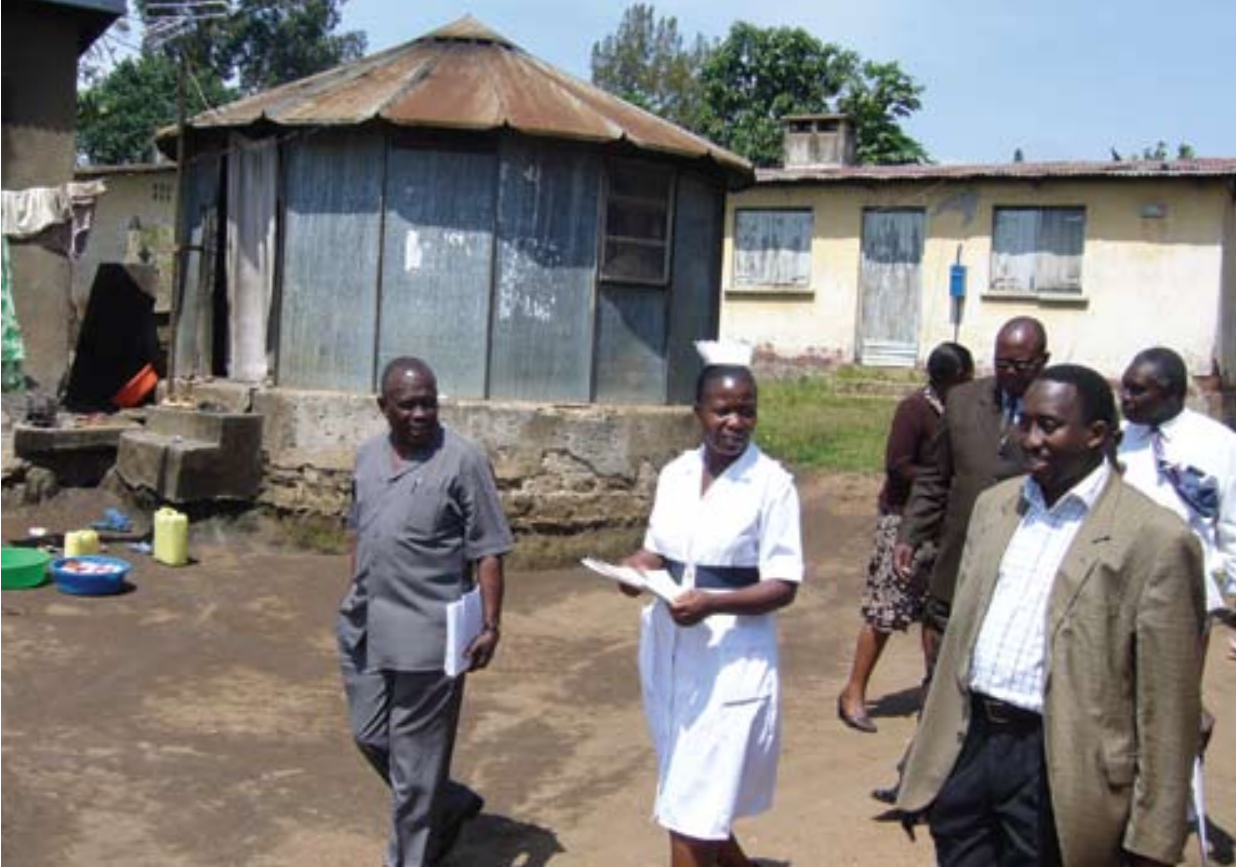

Geographic accessibility and local availability of services are also important factors. It has been demonstrated in many countries that as distance or travel time to health facilities increases, the use of health services decreases. Good roads, often a rarity in the poor areas of majority world countries, are required not only for people to go to health facilities but also for the easy distribution of drugs and other supplies, for timely referrals in emergencies and for better supervision of health workers. Common problems of limited hours, long waiting times, health workers who are absent from work and lack of drug stocks at public clinics are well documented in many LMICs, but their particular effect on the poor has not been well studied. Yet these factors are likely to be why many of the poor depend on informally trained providers and shopkeepers for health services, particularly as such providers may adapt a treatment course to match what the patient can afford. Wealthier families have more resources to travel to higher-quality clinics. Finally, the satisfaction with health services and people's perceptions of quality of care are also important determinants of the use of health services, though little research has been done on how the poor may be affected differently than the non-poor in LMICs.

Many of the factors affecting access are related to specific contexts or the way policies are implemented locally. A variety of strategies are shown to improve access to the poor in LMICs, including engaging government and civil society organisations and pursuing a wide variety of strategies to finance and organise services. Successful approaches involve concerted efforts to reach the poor, engaging communities and disadvantaged people, encouraging local adaptation and careful monitoring of effects on the poor. While innovations such as the use of health equity funds in Cambodia; a pool of money
Leaders of Kabarole District, Western Uganda, tour the houses that accommodate health workers at Buhinga Governmental Referral Hospital. Sources said that medical workers have shunned working at the hospital due to poor accommodation. Photo: (c) 2007 Bizimungu Kisakye, Courtesy of Photoshare.

to fund health costs for the poor, and conditional cash transfers in Mexico; cash for families dependant on conditions such as attending health check-ups have been shown to improve access by the poor, governments in LMICs rarely focus on the poor in their policies or the monitoring of health strategies. The challenge remains to find ways to ensure that vulnerable populations have a voice in how strategies are developed, implemented, and accounted for in ways that demonstrate improvements in access by the poor.

David Peters is an associate professor at the Johns Hopkins Bloomberg School of Public Health and Director of Future Health Systems; a centre that brings together policy makers and researchers to try and shape health systems to benefit the world's poor. Maria Au is currently studying for a DrPH in International Health at the Bloomberg School of Public Health.

This article is based on the recent paper by $\mathrm{Ma}$ ria Au and David Peters, Poverty and Access to Health Care in Developing Countries.

Radar Plot showing health use by economic quintiles (Low High Ratio) across regions and different health services

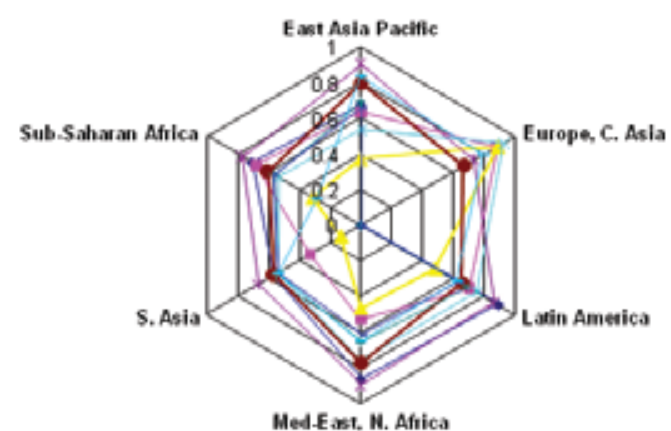

Med-East. N. Aftica
- ANO br medically traned - Immunization (qual basic coverages - Medicaltreatment of fever 


\section{Public Developing accessible health systems}

\begin{abstract}
There are two types of health systems in the world, public and privatised, though in practice virtually all national systems are some form of hybrid. TIM ANDERSON argues that these two opposing models drive much of the dynamics of health systems.
\end{abstract}

$\mathbf{T}$ he best health outcomes (i.e. low preventible disease and low critical mortality rates) come from those countries which have:

- publicly-funded and well-coordinated systems

- universal free access to health services

- large numbers of trained health professionals

- effective health promotion programmes

- high general levels of education.

These factors are more important than total money spent on health.

Amongst the wealthy countries, virtually all of western Europe has guaranteed universal and free access to health services; the United States of America does not. The US has a semi-privatised system where private health insurance is required to access health services. Yet almost $20 \%$ of the US population does not have such insurance and so can usually only access free medical care at a hospital emergency ward. A wealthy private health industry sits at the centre of the US system, driving up costs. The US spends $13.9 \%$ of its total GDP on health, yet has worse health outcomes (e.g. in infant and maternal mortality) than virtually every country in western Europe, where the biggest spender is Germany, at $10.7 \%$ of GDP.

Nevertheless, the US semi-privatised model has been promoted in OECD aid programmes, on the basis that 'public-private partnerships' and 'resource pooling' will add to the overall effort. A World Health Organisation panel, chaired by Jeffrey Sachs, also called for a multibillion dollar injection of funds into majority world countries' health systems. It is a central element of such 'big money' notions that private capital will be a central driver of health improvement.

Yet effective majority world country health systems are mostly undermined by privatisation and private insurance schemes. The Mexican health system, like the US system, shows us some of these problems. This system combines tripartite social security insurance bodies (with contributions from employees, employers and government), a public system and a large private sector. It has substantial resources and expertise but is fragmented, with highly unequal access to services. All formally employed Mexican workers must belong to a social security/health institution.
The IMSS (Instituto Mexicano de Seguro Social) is the biggest of these, with about $40 \%$ of the population, including workers' families. However, around $40 \%$ of Mexicans have no formal employment and therefore no health cover. In Chiapas state more than $80 \%$ of the population has no health insurance.

Each Mexican insurance institution has its own funding arrangements, facilities, doctors, nurses and auxiliary personnel. They could be separate empires, except that the federal government has begun to play a coordination and funding role, in response to the poor levels of insurance cover. The private sector is far more expensive, with around half

\section{More money, under privatisation, delivers Iless}

the country's expenditure and much higher doctor's wages. Yet while it consumes half the system's resources, it provides only $30 \%$ of the systems beds and $32 \%$ of the consultations, focussing mainly on curative medicine. The public health system has to carry most of the preventive programmes.

By way of contrast, just across the Caribbean is socialist Cuba, with an almost completely public health system, and the best health outcomes in Latin America. With a much lower per capita spending on health than Mexico, Cuba has half Mexico's tuberculosis infection rate, half the rate of underweight children, one third the HIV infection rate and less than one third the infant mortality rate, according to the United Nations Development Programme. Many of the elements of the Cuban model are similar to the good European public systems, but Cuba has done it with far less resources, demonstrating that good health need not be a luxury. Cuba has consistently prioritised health as a right and has committed to training large numbers of health professionals.

This small country has also developed the largest doctor training programme in the world, offering free scholarships to thousands of students from over 60 countries. Cuba does this with a belief that there is a shortage of health professionals in the world, a shortage made worse in majority world countries by the "brain drain' of doctors migrating (and being encouraged to migrate) to wealthier countries.

In summary, processes of privatisation have a series of debilitating effects on the health systems of majority world countries. Resources are wasted and unequal access to services is entrenched. The coordination of health systems, along with health promotion and prevention, is undermined. Training of doctors and other health professionals is restricted to a small elite. More money, under privatisation, delivers less. The solution must be a restoration of ethics in public health, affirming basic services as a right and not a traded commodity. Good health is not beyond the means of majority world countries.

Tim Anderson is a senior lecturer in political economy at the University of Sydney, his research interests include health systems, economic rights, rural development and autonomous development and trade initiatives. He pr]oduced the film The Doctors of Tomorrow (2008) about the medical training partnership between Cuba and East-Timor.

Health Clinic in Cuba. Photo: MG Harris.

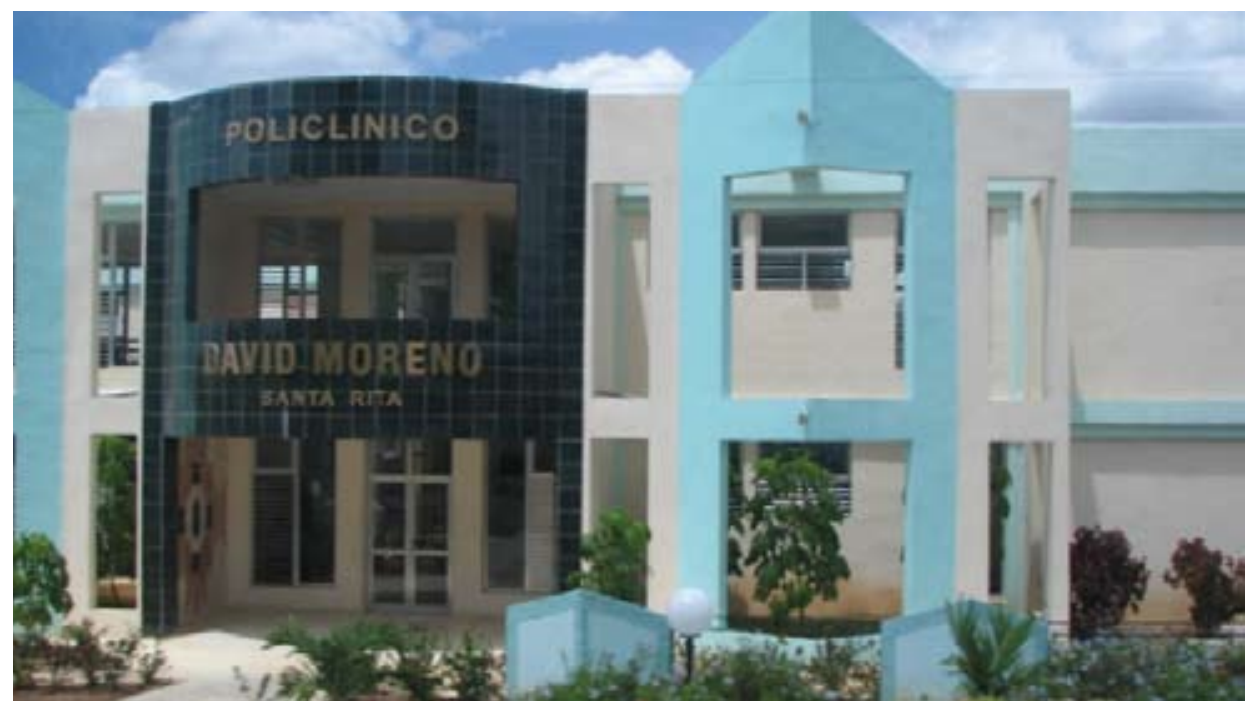




\section{HIV and AIDS medicine:}

\section{Trade law, diplomatic pressure, and the future supply of generics}

\begin{abstract}
THOMAS OWEN tells us that the future supply of generic medicines, which allow people around the world to access affordable health care, is under threat from big pharmaceutical companies.
\end{abstract}

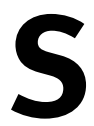

ince the formation of the World Trade Organisation (WTO) in 1995, accessibility of essential medicines across the globe has largely been determined by trade law - in particular, laws regarding intellectual property and patents. Before the 1990s, many countries did not grant patents on pharmaceutical products, considering medicines a public good to be regulated following domestic needs and means. With the passing of the WTO's TRIPS Agreement (Trade Related Aspects of Intellectual Property Rights), however, the protection of pharmaceutical patents is now an obligatory requirement of all WTO signatories; a legal mechanism ostensibly designed to balance the accessibility of public goods with the private reward for their production.

This system is inherently asymmetrical, favouring wealthy countries over poor ones. Around $95 \%$ of all patents issued each year go to the top 15 minority world countries - a figure even higher for medical patents - creating an imbalance which sees the rewards for innovation head almost exclusively to the minority world while the higher costs fall upon those least able to pay. In the case of pharmaceuticals, the inability to pay often means death. Recent estimates cite $97 \%$ of the five million annual deaths from 'tropical diseases', HIV and AIDS, malaria and tuberculosis as occurring in countries with average incomes of less than NZ\$6,640 a year. Reflecting the lack of incentive for a profit-driven pharmaceutical industry to invest in products for low-income consumers, the proportion of all pharmaceutical patents directed towards tropical diseases has never exceeded more than around $0.5 \%$.

\section{DIPLOMATIC PRESSURE}

For these reasons alone it is unsurprising that many majority world countries initially resisted the TRIPS Agreement. When an early draft of the Agreement was released, thousands protested in the streets of India, calling the draft 'DDT' in light of the harmful effect they perceived it would have on national health. However, from the negotiations leading to the formation of the WTO up until the present day, it is apparent that the major mechanisms promoting stronger patent protection are not in fact the TRIPS Agreement itself, but rather the subsidiary pressures from minority world governments forcing majority world countries to go even beyond the requirements included in TRIPS.

One point often unclear in commentary on the issue is that TRIPS does indeed include flexibilities to override patent protection in the interest of public health. Compulsory licensing - the right to breach patent and import cheaper generic copies of medicines - is the clearest example. However, such flexibilities have rarely been taken advantage of, as when national governments have sought such measures they have typically found themselves threatened with trade sanctions, the removal of aid and trading privileges, and private sector lawsuits. Of particular influ-

\section{the window of opportunity which allowed India to build a thriving generics industry is now closing as global patent protection regulations catch up}

ence has been the United States Trade Representative's Special 301 programme that monitors other nations' intellectual property laws and recommends direct action, a manoeuvre which in one instance cost India NZ\$148 million in removed trade privileges when it spearheaded majority country opposition to the TRIPS Agreement.

In recent years the most effective means to increase patent protection and dissuade the use of compulsory licensing have been bilateral US free trade agreements (FTAs). Often referred to as 'TRIPS Plus' for their ratcheting-up of patent rules, 17 such agreements have been signed since 1995, almost invariably serving to strengthen the rights of large pharmaceutical companies at the expense of affordable drug access. With the recent struggles of the WTO's Doha Round and an uncertain future for trade multilateralism, it
Antiretroviral medication Zidovudine. Photo: Mike Blyth.

appears the number of such bilateral agreements will only increase. This is despite recent moves from the now Democrat-controlled US Congress to curtail some of TRIPS-Plus' furthest excesses.

\section{THE ACCESS TO MEDICINES MOVEMENT}

The saga of patents, trade and essential medicines over the last 15 years, however, is marked by contradictory trends. In the late 1990s a transnational coalition of activists and NGOs emerged to advocate for greater medicines access. Crystallising around a 1998-2001 lawsuit between the government of South Africa and a collective of multinational pharmaceutical companies, this loosely associated civil society coalition of minority and majority world organisations worked effectively to publicise the issue of medicines and trade law, lobby their own governments, and, importantly, began collaborating directly with majority world country governments in order to clarify their rights. In subsequent years such efforts appeared to bare fruit, with the clarification of compulsory licensing rights under TRIPS through the 'Doha Declaration' and 'August 30 Decision', and a statement from the US Government that they would no longer aggressively pursue unilateral pressure over medicine patents. Such moves, accompanied by increased attention to patents and medicines access in the World Health Organisation and United Nations, constituted what Doctors Without Borders referred to at the time as a 'full and frank re-appraisal of the role that a patent system plays in public health'.

Since 2001 the percentage of people receiving antiretroviral (ARV) HIV and AIDS treatment in majority world countries has increased from less than $5 \%$ to around $20 \%$. Several countries have used TRIPS flexibilities to import generic ARVs, and there are 
positive signs of some majority world countries establishing their own drug manufacturing capabilities. In addition, governments around the world have increased funding, which, combined with the assistance of massive philanthropic organisations to negotiate bulk-buying of drugs, has led to a multi-billion dollar Global Fund with an estimated $60 \%$ of its drug supplies generics. Given the new context, health specialists and global institutions are optimistically setting a goal of universal access to ARVs within the next few years.

\section{THE FUTURE SUPPLY OF GENERICS}

The crucial piece of this puzzle, however, is the availability of an affordable supply of medicines. In 2001, when Indian drug firm Cipla announced they could provide generic ARVs for less than a dollar a day, it shocked a market accustomed to major pharmaceutical companies' price tags of $\$ 10,000$ per patient per year. The increased competition of generic producers has forced prices down across the spectrum, a necessary catalyst for making other access initiatives possible.

In the global generic drug market, India is the undisputed heavyweight. At some current estimates, over half the people treated with generic ARVs in the developing world receive Indian-made drugs. However, the window of opportunity which allowed India to build a thriving generics industry is now closing as global patent protection regulations catch up. Where 1970s Indian patent laws conferred liberal restrictions on drug copying, 2005 law changes to bring India in compliance with TRIPS have significantly reduced these, limiting the drugs available for copy and forcing generics producers to pay higher royalties to the patent holders. Furthermore, as India's economic successes see it increasingly integrated into minority world markets, the incentives to invest in the relatively unprofitable and politically dangerous world of generics markets are diminishing. In short, India's economic interests, as now placed, have more to gain than to lose from stronger patent protection.

In the absence of generic competition, the brand-name pharmaceutical industry will enjoy a monopoly on production of medicines for under-served markets - a historically proven threat to the supply of affordable global healthcare. The new situation calls for a new response from access activists across the world. Where once a global collaboration of civil society, governments and international institutions was successful in achieving greater medicines access, is it now time to focus attention on securing sustainable production and supply?

Thomas Owen is a PhD candidate in the Department of Communication, Journalism and Marketing at Massey University, Wellington.

\section{Trade and access to medicines in Fiji and the Pacific}

\section{After spending time in Fiji talking with local stakeholders, SARAH MEADS} reflects on the need to boost awareness amongst policy makers of how trade can restrict access to medicines in the Pacific.

$\mathrm{n}$ the face of TRIPS-Plus style trade agreements, the ability of majority world countries to limit trade restrictions on health and economic development depends critically on how well they mainstream health into trade policymaking and how they cope with the forces of regionalism and the joining of the global trading system.

\section{AWARENESS OF TRADE AND ACCESS TO MEDICINES IN THE PACIFIC}

Last year I traveled to Suva, Fiji, to discuss with national and regional trade and health stakeholders the factors that shape $\mathrm{Pa}$ cific islanders' views of trade and access to medicines, and what steps are being taken to mitigate access issues. Discussions were timely because of negotiations between the European Union (EU) and 14 Pacific Island Countries to form an Economic Partnership Agreement (EU EPA). The EU EPA was likely to include TRIPS-Plus. Negotiations have since stalled, with Fiji and PNG signing separate agreements.

However, trade and access to medicines still has relevance at a national level, particularly for existing WTO members (Fiji, PNG, Solomon Islands, Tonga) and countries seeking to accede to the WTO (Samoa), because access to medicines is a key driver of intellectual property law reform. Additionally, TRIPS-Plus provisions may already exist in national patent law, for example in Fiji. Any future evaluation of a regional approach to intellectual property rights or medicines regulation (under the Pacific Plan) would also need to take this into consideration.

With the exception of several well-informed individuals, a general awareness of trade restrictions on access to medicines amongst some key regional and national trade and health stakeholders, and UN agency senior staff, appeared to be low when I visited Fiji.

There were several contextual factors contributing to this. More immediate challenges associated with the high cost and

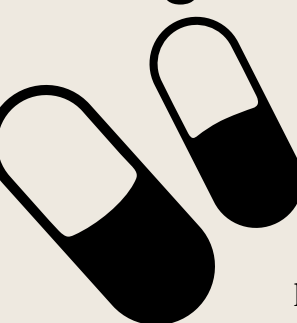

complex logistics of delivering curative healthcare to Small Island Developing States and, with the exception of Papua New Guin-

ea, the absence of a catalyst, such as an HIV and AIDS epidemic, are two examples. A cultural preference for traditional rather than western medicines, some evidence of health aid dependency, limited mainstreaming of health into trade policymaking and external pressures from regionalism causing policy misalignment amongst and between regional and national stakeholders are also key issues.

In contrast, awareness is elevated in other more economically advanced majority world countries (with HIV and AIDS) because these governments have begun to provide more comprehensive public healthcare services.

For example, in 2006 an estimate of the additional cost of TRIPS-Plus provisions contributed to the rejection of a proposed Thai-US Free Trade Agreement by the Thai government. A report commissioned by the Thai government estimated the cost of 60 core drugs could increase by NZ $\$ 122$ million if the patent was extended one year beyond the standard 20 year patent period, and up to NZ $\$ 10$ billion for ten years of patent extension. Among other TRIPS-Plus demands, the US typically seeks five year (or more) pharmaceutical patent extensions in Free Trade Agreements.

Improvements to current, declining population health trends in the Pacific region are crucial to the region being able to sustain any future benefits from economic development, especially if Pacific Island Countries have to absorb significant adjustment costs and suffer the loss of national sovereignty under the pressures of trade liberalisation and regionalism. As a consequence, national and regional health and trade stakeholders should start to acknowledge trade and access to medicines in their agendas, and begin to systematically implement a broad range of multidisciplinary responses to enhance access to health.

Sarah Meads is an independent consultant. She has postgraduate science and business degrees and recently completed a Masters of Development Studies at Victoria University. 


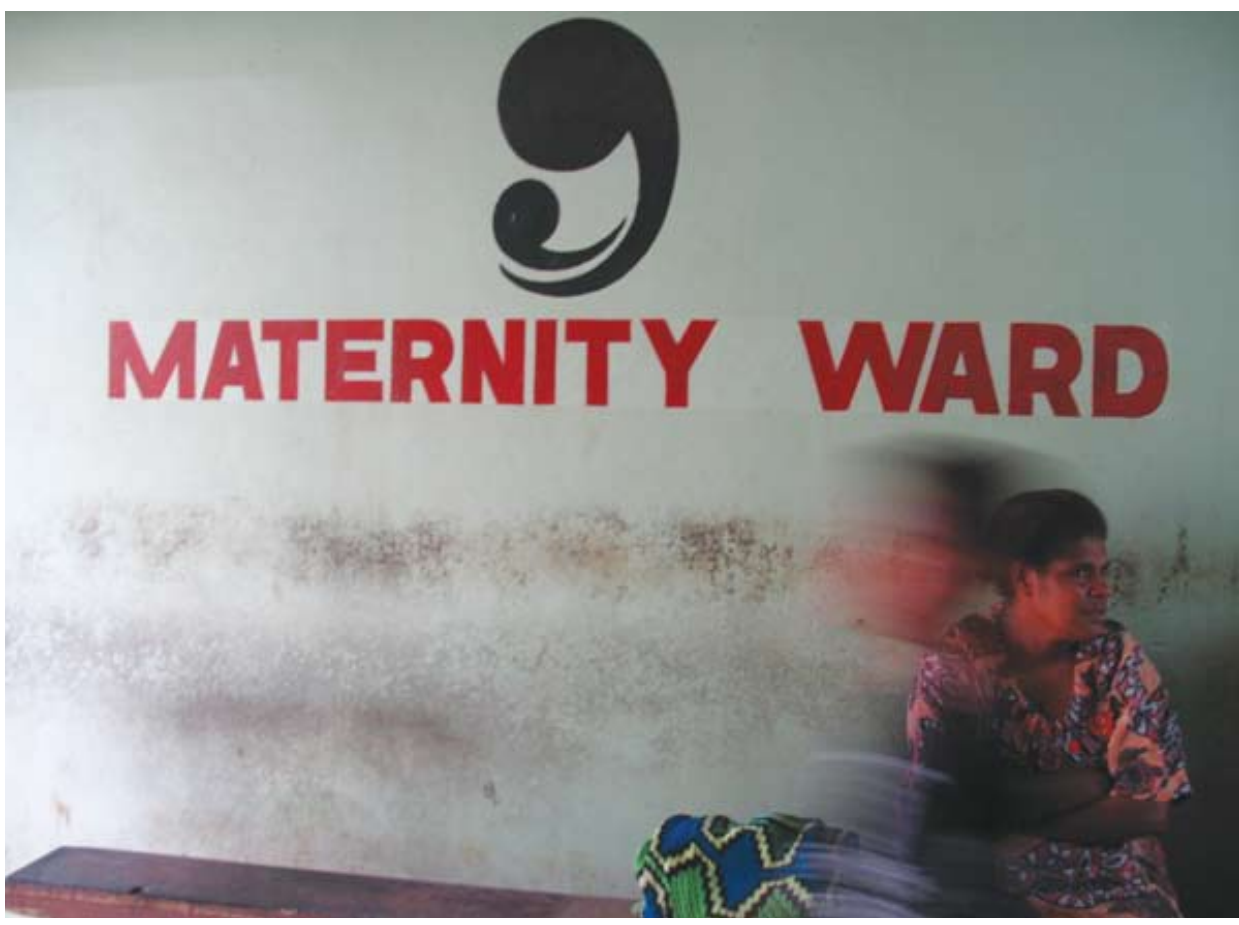

Waiting outside the maternity ward of a hospital in Kiribati. The maternal mortality ratio is 56 (per 100,000 live births) in Kiribati and 330 in PNG, compared with nine in Aotearoa New Zealand. Photo: Pedram Pernia and Asia Pacific Alliance.

\section{Falling short: Health and the Millennium Development Goals in the Pacific}

\section{MANORANJAN MOHANTY tells us that health is at the heart of development goals, but crucial health indicators in some Pacific countries are low - or even declining. \\ A VICIOUS CIRCLE}

Poverty, health and development (PHD) are closely intertwined. Health is critical to human development: good health of people is the 'wealth' of a nation; poor health drains a country's resources and is a major impediment to development. Poverty is both cause and effect of ill-health. Generally, the poorer the country, the lower the health status. Women and children are the most vulnerable group affected by the PHD syndrome; they are more likely to be of ill health, poorer and powerless, thus bear a 'triple burden'.

A 'vicious circle' of poverty, ill health and static or declining levels of human development continues to occur in the majority world - and the Pacific region is no exception.

\section{FALLING SHORT OF THE MDGS}

Improvements in health are key for achieving the Millennium Development Goals (MDGs), the roadmap for world development by 2015 . Of the 8 Goals, 21 targets and 48 indicators set out in the MDGs, at least 6 Goals, 9 targets and 20 indicators are specific to health and related issues. However, Pacific countries show wide ditional and locally produced foods towards imported and processed food has significant implications for health and disease. Urbanisation is also resulting in water and sanitation crises and solid waste problems, all contributing to poor environmental quality. Many Pacific Island cities and towns, such as Tarawa, Suva, Honiara, Nuku'alofa and Port Moresby, have per capita water consumption levels much lower than the World Health Organisation's (WHO) prescribed level of up to 250 litres per person per day. As a result, the incidence of water and waste-borne, environmental sanitation-related and lifestyle diseases have increased in significant proportions. Incidence of malaria is very high in the Solomon Islands and Vanuatu, and incidence of typhoid and dengue fever are growing concerns in Fiji.

\section{DYING YOUNG}

Unlike African and Asian regions, the $\mathrm{Pa}$ cific is affected not so much by under nutrition and diseases such as diarrhea, dysentery, and TB that are associated with poverty, but rather by over nutrition, obesity and lifestyle diseases such as diabetes, hypertension and heart disease. These conditions are commonly associated with relatively higher levels of development, yet it is low-income people that may be most vulnerable to lifestyle related disease.

The leading non-communicable diseases of the Pacific region, according to PACNEWS reports, are diabetes, nutrition-related disease and cancer. Fiji's diabetes rate is one of the highest in the world - it is estimated that one in seven people in Fiji has diabetes and its prevalence is increasing every year. The WHO has noted an alarming death rate of $75-80 \%$ from non-communicable diseases in the Pacific. Tobacco smoking, alcohol and substance abuse, physical inactivity and an unhealthy diet are the main causes of such diseases. Consequently, many people in $\mathrm{Pa}$ cific countries die young.

The incidence of HIV and AIDS is also on the rise in the Pacific region, particularly in PNG. The spread of this virus has a drastic impact on human lives, particularly on women and children.

Health awareness campaigns and programmes, and more investment in the health sector are badly needed in the Pacific region. NGOs and civil society organisations have a greater role to play in health awareness campaigns and health advocacy if we are to achieve the MDG targets and climb out of the vicious circle of poverty, health and development.

Dr Manoranjan Mohanty is in the teaching faculty of Development Studies at the School of Governance and Development Studies in the University of the South Pacific, Suva, Fiji. 


\section{Mãori and the cancer journey}

Highlighting the startling differences between cancer rates for Māori and non-Māori, THE MĀORI EXPERIENCES OF CANCER

RESEARCH TEAM uses their recent research to show both the barriers and possible solutions to resolving this inequality.

\section{CANCER: SOME STARTLING INEQUALITIES}

Cancer is a big killer in Aotearoa New Zealand. Most of us know someone who's had it, and many of us have lost loved ones to cancer. But there is a shameful side to the cancer picture in Aotearoa NZ; recent research shows the unequal impact of cancer in our country, where one group has been identified as suffering more from cancer than others.

Māori are more likely than non-Māori to get cancer, and Māori are almost twice as likely as people in other groups to die of cancer.

These concerning figures come from studies by researchers at the University of Otago, who examined the census mortality figures and looked at data from other cancer reporting systems. They show some positive trends over recent decades with cancer deaths declining among non-Māori, non-Pacific people. But for Māori the news is not so good. Over the period 1981 to 2004, while the rate of deaths from cancer declined among nonMāori, non-Pacific people, Māori cancer mortality rates went up. The cancer inequalities gap is widening.

\section{WHAT'S BEHIND CANCER INEQUALITIES?}

With these statistics in mind, a team of researchers based at Victoria University of Wellington looked at some of the explanations for these inequalities in the literature. The researchers found that in the studies that have been done, the focus tends to be in three key areas - health system, healthcare process and patient factors. They also identified that:

- access to cancer care is 'complex and multidimensional'(Cormack et al.)

- financial and cultural factors, amongst others, are key barriers to healthcare for Māori (Jansen and Smith)

The researchers noted that the studies highlight complex health issues that require both urgent action and an understanding of their root causes.

One of the root causes identified in the literature was racial discrimination. For example, a study by Harris et al. based on data from the 2002 - 2003 National Health Survey, identified discrimination as a key root cause. The study found:

that self-reported experience of racial discrimination was highest among Māori and that any such experience was strongly associated with negative health effects equally for all ethnic groups.

Further, recent work by Reid and Robson states that: racism is a major determinant of health and a fundamental driver of inequalities that must be addressed in order to improve Māori health outcomes and reduce inequalities.

\section{QUALITATIVE RESEARCH: MĀORI EXPERIENCES OF CANCER}

As well as identifying causes from other literature, the team of researchers at Victoria University worked with Māori providers and the Cancer Society to explore some Māori experiences of cancer.

The researchers conducted a series of hui (focus groups) and face-to-face interviews across Manawatu, Horowhenua and Tairawhiti. This was followed by a feedback hui to check their results and further their understanding of key themes.

\section{SOME POSITIVE EXPERIENCES...}

The participants had high praise for Māori health providers. These organisations were seen to be grounded in an iwi worldview and to have a holistic style of healthcare practice that was warmly valued. 'Māori health providers will go that step further', said a participant.

Practical assistance from Māori providers, such as transport to the doctor or hospital or delivering prescriptions, was important to cancer patients and whānau, as was the recognition of their taha Māori (Māori being).

For Central Districts patients using the Regional Cancer Treatment Service in Palmerston North, there is a residential facility called Ozanam House. Patients and family members can stay free of charge in a wellequipped whānau house, which reduced the negative impact of having to be away from their homes. People could come and go as they wish, and Ozanam house provided help for patients and whanau to get to treatment sessions. Participants valued this service and reported, 'you can talk with others about your experiences, and you cook your own food'.

\section{...AND SOME MIXED AND NEGATIVE EXPERIENCES}

Crengle et al. studying the same data as Jansen and Smith, showed that general practitioners have lower levels of rapport and spend less time with Māori than with non-Māori patients. The researchers at Victoria University found that participants had both positive and negative experiences with doctors, nurses and hospice staff. They particularly valued good communication, but some stated that some health professionals were not responsive to their needs, or had poor attitudes. Nurses were important in providing services, information and support. Ultimately, with health professionals, their ethnicity was less important than their personal qualities of competence, warmth, compassion, honesty, respect, and meeting people half-way. Understanding that whānau are often highly involved in the patient's cancer journey, and supporting this, was also important.

\section{MĀORI DESERVE THE SAME SERVICE AS OTHERS}

The research came up with some suggestions about how some of these inequalities can be addressed by improving cancer services including:

- coordinated service delivery

- meaningfully informing Māori of their entitlements

- better resourcing of Māori providers

- altering mainstream services to support Māori

- increasing the Māori health workforce

- cultural competence training for all health workers

- the use of people (system navigators) to guide patients through the treatment process

- the inclusion of whānau in the cancer control continuum and adequately resourcing them.

The Māori Experiences of Cancer Research Team is based at Victoria University of Wellington and consists of Tai Walker, Louise Signal, Marie Russell and Kirsten Smiler. Others involved with this research are Rawiri Tuhiwai-Ruru, Otaki Community Health Centre, Te Wakahuia Hauora, Te Aitanga a Hauiti Hauora, and Turanga Health. The research was funded by the National Scientific Committee of the Cancer Society of New Zealand (Inc.). The New Zealand Medical Journal, August 2008, includes a full report on the research.

From Unequal Impact. Maori and non-Maori cancer statistics: 19962001. Te Rōpū Rangahau Hauora a Eru Pōmare. Wellington School of Medical and Health Sciences, Wellington. p.32.

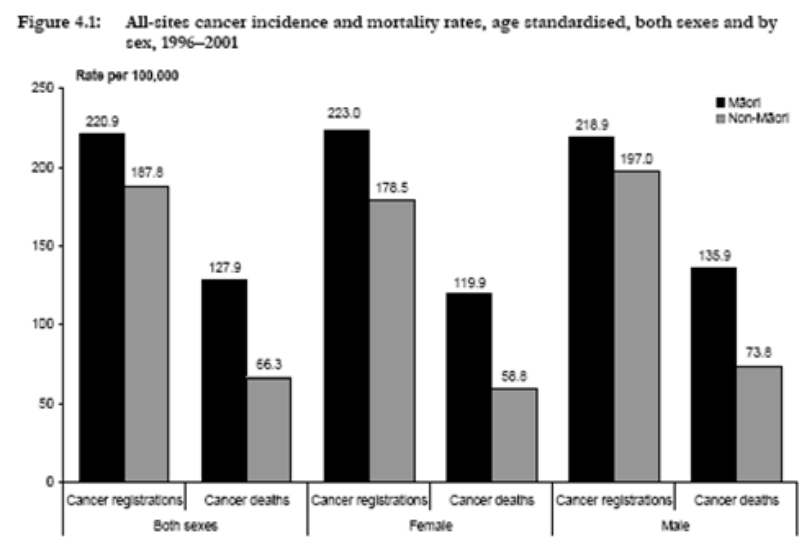


GROUP OF WOMEN FROM THE

\section{SOMALI COUNCIL.}

\section{ISSUES}

I think the key issue affecting access to health for Somali people is language. People should have access to interpreters, but some medical centres have no funding for African interpreters. Also, the whole health system here is difficult to understand. It's a dilemma for anyone, let alone those of us coming into this society!

Sometimes pamphlets are produced in Somali language, but some of our people don't read or write in their own language. That's why having an interpreter is important, because when they're there from the start the person can understand what is happening, and they can go back and ask the interpreter later. Sometimes they just use a family member, usually a child, because not all health centres have an interpreter available. But you can traumatise a child with the medical terminology you are using, and they might think, 'Oh, my mum is going to die'. Imagine making a kid go through that. And if the child misses something, they won't be able to explain properly. So it comes back to a lack of trained interpreters.

Many doctors say they have no funding for interpreters, but they don't understand how important it is. There was one situation where a doctor prescribed medicine to a woman with a sick child. The medicine was supposed to be externally used but she didn't understand, and there was no interpreter. She fed the medicine to the child internally. Lucky it wasn't a dangerous medicine, but it could have been much worse.

So the main limitations are funding for interpreters and knowledge about the health needs of different groups. And also commitment - whether the medical staff are committed to spending the time to book and use a translator. Some people say they don't have time, but if they don't use an interpreter, then the person won't get better, won't understand their treatment properly, and will go through more stress. So you're prolonging the impact of that stress on them, which is not fair.

It is also people's mindset. We come from a mindset where you only see a doctor when you are critically ill, and we don't have preventative kind of measures. Also, in our country, people are used to buying medicine from the counter, but here it is very different; the doctor has to prescribe medicine and sometimes the
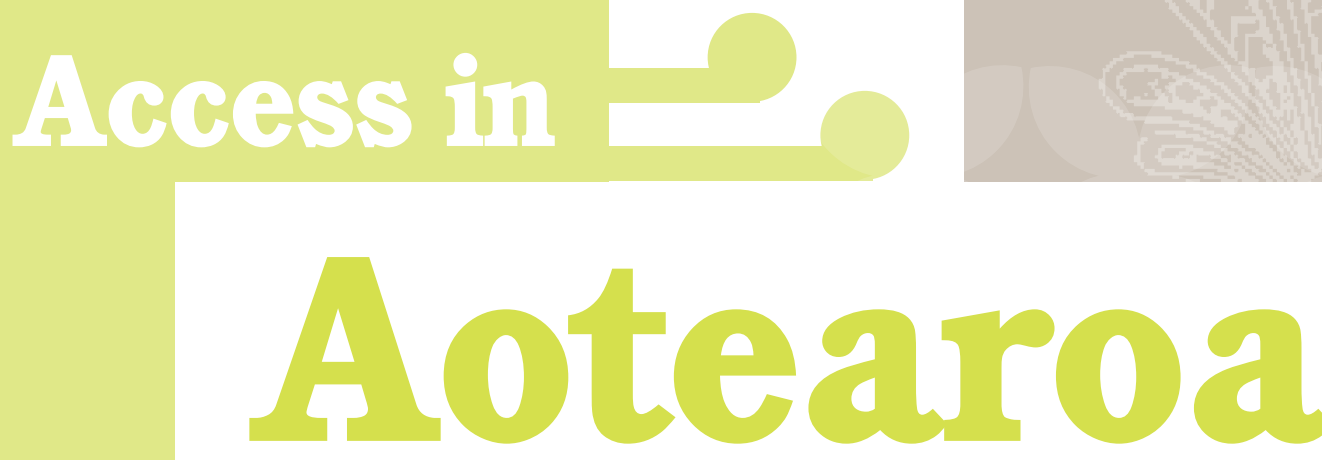

doctor doesn't prescribe anything and the patient gets angry. They think the doctor doesn't know what they're doing because they haven't prescribed anything. Back home you get an injection for everything, and you're told that what you get will fix you. Here, people don't trust doctors because the doctors say they haven't got all the answers. That trust has to be built up over time.

\section{SOLUTIONS?}

We have organisations like ours, the Somali council, in the community. We also need commitment from practitioners, and more training for them so they understand refugees' health needs. We are working towards a national strategy with guidelines for working with refugees that every medical centre can follow. Amongst the African refugees, $60 \%$ of the population is between $10-29$, so if we don't have a strategy in place, this population will grow and the health problems will grow.

Every person has a right to access information - Right 5 in the disability

code. We have a right already

there, why can't we

respect it?

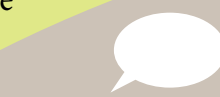

FLORA TOMA, interpreter, community support worker and Assyrian Women Group's leader.

\section{ISSUES}

I agree with the women from the Somali community; language is also the main barrier for us, especially when we go to the hospital. The young people don't have a problem with language, but for people in their 40s and above, about $60 \%$ of our community, they can only speak basic English, not enough to understand medical terminology.

The Aotearoa New Zealand health system is also difficult for us to understand. In our country, if I have a stomach ache, I go immediately to a specialist. You do pay, but only NZ\$4-5 to visit a specialist; it is cheap and there is no waiting list. We are not used to the system here, and people don't understand that they have to be referred to a specialist and then wait so long for an appointment.

\section{Three community}

\section{leaders take a look at}

\section{the access issues facing}

\section{groups in Aotearoa}

\section{New Zealand}

Some health centres in Aotearoa NZ provide translators for patients, but others don't, and most of the people in my community complain about this. The situation has gotten worse in the last couple of years, partly because hospitals complain that it costs too much to provide interpreters. The medical staff used to say to people, 'Don't bring a family member, you need a trained interpreter'. But now, they sometimes ask people to bring family members because they say there is no funding for more interpreters. This is not right. I am an interpreter, but imagine if I have to interpret for my mum - if the doctor says something bad, how could I tell her?' There is a language line that provides translation over the phone, but people say it doesn't work well because the interpreters on the line may not speak fluent Arabic, so sometimes they have to reschedule the appointment because they can't understand anything.

\section{SOLUTIONS?}

I am a leader of a women's group, and we hold meetings during the year where we bring in speakers on different aspects of health to talk 
devised for me, from medication to changing lifestyle, nothing much is going to improve for me. They are the ones that may cook my meals and provide transport and encouragement.

For us, some cultural aspects of health are also important but not widely acknowledged; one example is traditional medicine. Often traditional medicine takes priority over conventional medicine for Pacific people, and we need both for well-being. I believe we need to integrate traditional and conventional medicine more, so that when Pacific people visit their doctors, they are not reluctant or afraid to say that they are also using or thinking of seeking traditional treatment.

Language is also a problem, and this is not just a lack of interpreters, but proper interpretation clinically or medically. Miscommunication between the generations can be an issue. Often the older Pacific generation doesn't speak much English, and may not read or write; whereas the younger generation often speaks English and may not have a complete understanding of their Pacific language. This causes problems. When older people visit their doctors, they sometimes expect their young people to interpret for them, but the interpretation may not be accurate, and cultural nuances may be missing. Most information available is not printed in all Pacific languages.

Access to health is also about peoples' socio-economic position. Māori and Pacific people always rate higher in statistics when it comes to cardio-vascular, diabetes and cancer to name a few. Now we are being labelled as an obese people. I believe this will get worse because of the environment we live in. Pacific people often have low-paid jobs; unemployment is rising; many people have large families and living conditions are crowded. Treatment costs can be very high.

In Aotearoa NZ, fast food is much cheaper than nutritious food, so when it comes to budgeting, healthy food may not rate as a priority. The answer comes down not only to education, but also to changing the socio-economic factors that influence people's well-being.

\section{SOLUTIONS}

We need to recognise and foster closer relationships and partnerships with Pacific communities from families to church groups, local government and health authorities to work towards a sustainable environment. Furthermore, we need to develop a Pacific workforce and support and develop community leadership as part of addressing disparities in accessing health.

\section{Links from the Knowledge Centre}

He hononga mai I te pūtahi mātauranga www.dev-zone.org/knowledge

Our cities, our health, our future. World Health Organisation, 2008

This report explains the context, the challenges and the actions needed to improve public health in cities. It is enriched with photographs, case studies and charts.

Global Health Watch 2. People's Health Movement, GEGA and Medact, 2008

This was created as an alternative to the World Health Report, in response to criticisms that WHO reports were inadequate; that there was no report that monitored the performance of global health institutions; and, that the dominant neo-liberal discourse in public health policy also needed to be challenged by a more peoplecentred approach that highlights social justice.

Achieving the millennium development goals: Does mental health play a role? J. Jaime Miranda and Vikram Patel. PLoS Medicine, 2008

The authors argue that the Millennium Development Goals (MDGs) practically define health efforts in the 21 st century, but they virtually ignore non-communicable diseases such as mental health. The authors argue that tackling mental health problems will be vital to achieving the MDGs; in particular three goals - eradicating poverty, reducing child mortality, and improving maternal health.

Cultures and contexts matter: Understanding and preventing HIV in the Pacific. Carol Jenkins and Holly Buchanan-Aruwafu. Asian Development Bank, 2007 This publication examines in rich detail the cultural and contextual issues that have shaped HIV transmission in the Pacific. The authors also discuss the implications of contexts and cultures for designing and implementing HIV prevention and treatment programs.

\section{Health in ruins: A man-made disaster in}

Zimbabwe. Physicians for Human Rights, 2009

This report examines Zimbawe's health system, arguing that the deterioration of healthcare is a breach of the right to health of the Zimbabwean people.

\section{Ending the R\&D crisis in public health:} Promoting pro-poor medical innovation. Oxfam, November 2008

Diseases that disproportionately affect the majority world cause immense suffering and ill health. Delivering appropriate medicines and vaccines for those in the majority world requires reforms to the existing research and development system and a willingness to invest in promising new approaches.

\section{Oceania Society for Sexual Health and HIV Medicine}

A society formed by doctors to ensure that people living with HIV and people affected by sexual health problems in the Pacific receive the best possible care. people's attitudes are changing. 


\section{Championing Mental Health in the Pacific}

Access to mental health services is a vital but often overlooked area of health. MARGARET LENISTON takes a look at the problems young people in the Pacific face, and the ways they are taking action to increase understanding and access.

$\mathbf{T}$ he stigma and discrimination faced by people with mental illness can be debilitating. This stigma, accompanied by limited mental health services, means many people are not the getting the help they need.

The experience of those working in the mental health sector reveals that there are additional reasons why people are choosing not to access mental health services. There is misinformation about what mental health is and a lack of knowledge of the need to seek early assistance to treat it. Many do not understand the causes of mental ill health or how to develop coping strategies to maintain sound mental health.

This is particularly important for our young people. Work is being done to improve the mental health environment by organisations such as The Foundation of the Peoples of the South Pacific (FSPI) and the NZAID funded Pacific Island Mental Health Network. The FSPI Youth Mental Health Situation Analyses in Tonga, Tuvalu, Solomon Islands and Samoa and Masculinity Mental Health and Violence studies in PNG, Fiji, Vanuatu and Kiribati have given young people a voice and throw light on the mental health issues that concern them.

These studies indicate that youth are particularly vulnerable, in part, because of rapid changes brought about by the influence of global values on their traditional cultures. Although differing for men and women, the reports show that a lack of voice and economic opportunity, the absence of good social environments and of a stable and good political leadership exposes young people to a range of new risk behaviours.

A youthful and creative response to address the stigma and discrimination around mental health is the newly formed and very successful youth advocacy group, the Youth Champs for Mental Health (YC4MH). Formed out of consultations during the development of the Fiji National Suicide Prevention policy, YC4MH started by bringing together representatives from a diversity of youth affiliations. The initial consultation forum was a success with participants sharing personal stories, views and experiences. At the end of the forum the participants stood up and challenged each other to continue advocating for mental health issues. They wanted to target

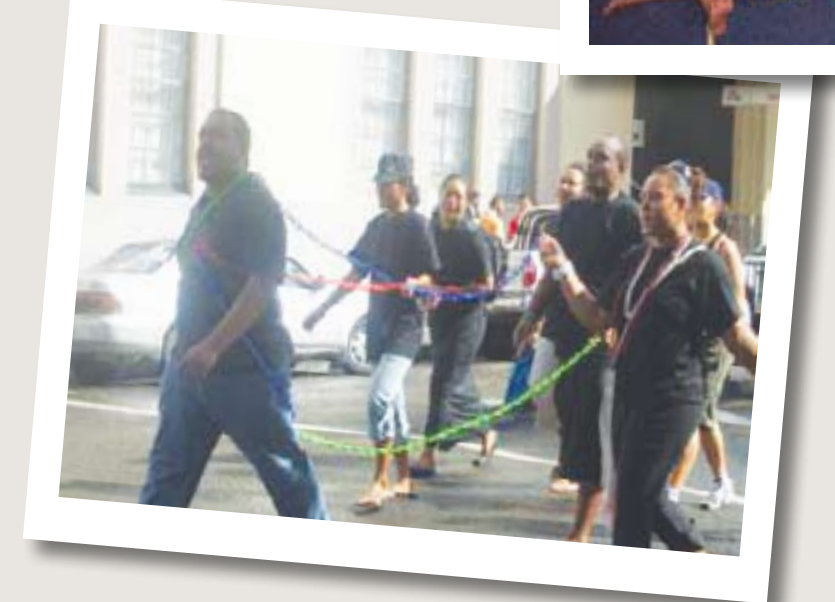

Above: PCDF/FSPI Mental Health Education and Awareness Youth Camp - Youth Champs for Mental Health (YC4MH). Photo: PCDF Partners in Community Development (FSPI Network Partner).

Left: The Youth Champs for Mental Health use drama to share their views at the Suicide Prevention Policy Consultation workshop organised by Fiji Ministry of Health, UNESCO and PCDF (Fiji YMH Project Implementer). Photo: FSPI.

other youth and felt that the best way to do this was through themselves, using a 'Youth 4 Youth' approach.

Following the forum, the YMH Partners in Community Development (PCDF) organised other Youth and Mental Health related activities. The same young people attended. Their engagement provided PCDF with an indicator of their commitment to mental health issues. PCDF then organised an awareness camp for these youth to provide training on mental health. The camp was such a success that they formalised the 'Youth Champs 4 Mental Health' group.

\section{Many do not understand the causes of mental ill health or how to develop coping strategies to maintain sound mental health.}

The YC4MH's main objective is to help reduce mental ill health stigma through a range of creative advocacy activities. Beginning with only 14 members the YC4MH numbers have now grown to about 30 . In less than one year, YC4MH have coordinated an array of creative advocacy and promotion activities on mental health issues using a range of performing arts.

One member, Gary Rounds, won the Fiji Poetry Slam with his touching poetry performance of his own story of suffering mental illness, 'We are gonna keep on walking. This poem inspired another within the group,
Koni Fiu, to turn it into a song. This composition was performed by the Pasifika Voices (ex Malaga) choir conducted by the highly regarded Igelese Ete.

The National Council for the Prevention of Suicide approached the youth champs and asked them to assist the Rishikul Sanatan School in developing their suicide prevention themed performance for Tadra Kahani, a national school dance and music performance. The youth champs visited the school to provide basic mental health and suicide prevention information to the performers and to guide them through their concepts. The school went on to win the school competition. YC4MH have also been working with the Ministry of Health, PCDF and others to contribute to concepts on the Dare to CareStop Stigma Campaign.

The YC4MH have showed a strong commitment to reducing stigma through demystifying the misconceptions, ignorance and negativity about mental health issues. Tiriseyani Naulivou, the PCDF Youth and Mental Health Coordinator said:

We want people to realise that they should not be ashamed of accessing mental health services. Just as people feel free to visit a diabetes health centre, people should also feel comfortable accessing a mental health service centre and that mental illness is just another illness that may be able to be prevented.

Margaret Leniston is the Regional Health Programme Manager at the Foundation for the Peoples of the South Pacific International (FSPI) - margaret.leniston@fspi.org.fj 


\section{Money isn't everything: health aid effectiveness takes time}

\section{CARMEL WILLIAMS and GARRY BRIAN from the Fred Hollows Foundation argue that aid money won't solve health problems in the Pacific unless the fundamentals of healthcare are in place.}

H ealth initiatives in majority world countries were out of fashion in the 80 s and 90 s. They are now the subject of much attention and funding with health aid commitments doubling from NZ $\$ 8.9$ billion in 2001 to NZ\$20 billion in 2005.

This unprecedented attention to health aid has sparked a debate: can access to health services and health outcomes improve as rapidly and sustainably as donors might hope? Those urging caution about quick results warn that it requires changes in entire healthcare systems to improve population health in the majority world and that quick cash-flows cannot readily resolve all the problems. Some argue, with good evidence, that 'vertical programmes'; pushing large funding flows to single diseases, such as HIV and AIDS or malaria, can even result in worsening health generally if basic health care is overlooked. Others take the position that vertical programmes can actually help to build health systems. Contributing to the complexity of these issues is the worldwide shortage of healthcare workers and their attrition from majority world countries.

This debate over whether money is more effectively spent on short-term, large injections of funds into vertical programmes, or longer term approaches addressing 'wholeof-health' factors, can be contextualised with eye care services in the Pacific.

The population of the Pacific region is about nine million, and about $85 \%$ of its people live in rural or remote settings without easy access to health services. The need for eye care is undeniable, with over 80,000 people blind and hundreds of thousands visually impaired. Up to $75 \%$ of these people could have their vision restored through surgery or by wearing spectacles.

Provision of healthcare here is challenging. It is delivered almost exclusively in the public sector and across difficult geography. It receives low per capita government funding, has very low ratios of doctors and nurses to population and inadequate infrastructure. These challenges contribute to the region's poor health indicators.

Barriers exist at all levels and improvements to eye health require increased undergraduate medical and nursing training capacity, increased general health capital works and equipment acquisition, sufficient ongoing funding for staff employment and service provision, improved health service management systems, workforce retention, and community work to promote access to, and use of, eye care service.

Pacific doctors train at either the Fiji School of Medicine (FSM), which has an annual intake of 70 students, or the University of Papua New Guinea (PNG), from where about 20 graduate each year. Between 1987 and 2002, despite 284 Fijians graduating from FSM, Fiji suffered a net loss of 226 doctors. The target and actual medical workforce in PNG for 2005 were 597 and 275, respectively. Both these countries are desperately short of health personnel and report high rates of attrition of workers, particularly to Australia and Aotearoa New Zealand.

To address eye health across the region, there is a need for one eye doctor and four eye nurses per 100,000 population, equating to 90 eye doctors and 360 eye nurses. With only 15 Pacific eye doctors and 65 eye nurses currently employed in the public sector in the region, this represents at least a four-fold increase.

If donors adopted a vertical model of aid support, and injected significant funding to eye health, and if Pacific ministries of health agreed to increase eye care workforce numbers to this extent, medical and nursing schools could not address the shortfall quickly. There would be a training lag time of at least six and three years respectively. Suddenly seducing a large number of doctors and nurses into eye care training would deplete the potential and actual workforce for other essential health services and disrupt national workforce planning. The public health sector would not have the capacity to employ all the new recruits in a short timeframe.

Using donor funds to establish stand-alone clinics for eye health services would also be fraught with difficulty. Over the past 15 years, $50 \%$ of medical aid centres established in PNG closed through lack of maintenance. Sustainable eye clinics need reliable supplies of spectacles, medicines, and other consumables. Such supply lines are not routinely in place in the Pacific, and given policy, financial and managerial realities, will take some years to establish.

Finally, even if well-managed and staffed eye clinics are available, it does not automatically follow that the community uses the service. Research in Timor-Leste and PNG has shown that people with curable blindness and visual disability, especially women, fail to access eye care because they are unaware of services, cannot afford transport or hospital fees, fear hospitals, doctors and surgery and accept failing eye sight as an inevitable aspect of ageing. Community education is needed.

The scale of such a 'whole-of-health' approach should not discourage health ministries and NGOs from embarking on programmes to improve care, yet neither should donors and advocates expect to see miraculous and sustainable results without the fundamentals of healthcare in place.

Carmel Williams and Garry Brian are from the Fred Hollows Foundation NZ, an Aotearoa NZ-based international NGO involved in eye health education with partners in PNG, Fiji and Timor-Leste.

Aven with her family as she sets out on the three day journey to join The Fred Hollows Foundation NZ eye camp at Kirakira Hospital , Makira-Ulawa Province, Solomon Islands. Photo: Kristian Frires.

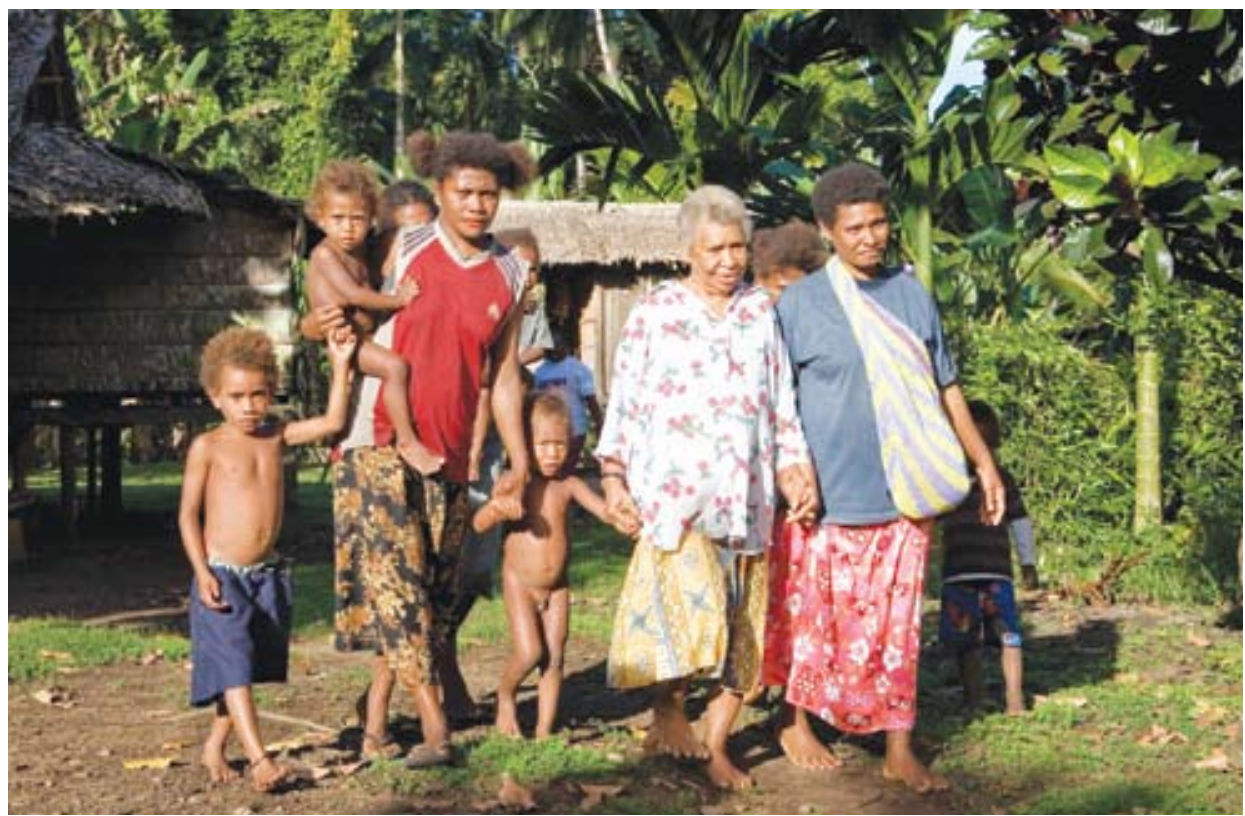




\section{Building a healthy future for women}

\section{MELAN IE HEAPHY from NZAID paints an alarming picture of the state of women's health, and argues that more needs to be done to improve access to health for women around the world.}

$\mathbf{W}$ orldwide, women and children are significantly over-represented amongst people living in poverty and are much more likely than men to be poor, malnourished, illiterate, and have inadequate access to basic health services. Statistics show that girls are twice as likely as boys to die from malnutrition and preventable diseases.

Discrimination on the basis of being female restricts the access of women and girls to healthcare in many countries and cultures, affecting their overall well-being and quality of life. Low levels of access to healthcare and information leads to many health hazards, including under-nutrition, death and chronic illness from childbirth, high birth rates, sexual and physical violence, and increasing rates of illness such as sexually-transmitted infections, HIV and AIDS, malaria and respiratory diseases.

According to the United Nations Population Fund, a woman dies during childbirth every minute; for every woman who dies, there are 20 more who experience serious complications. In Papua New Guinea (PNG), a woman is 50 times more likely to die in childbirth than in New Zealand and the latest statistics suggest that maternal mortality in PNG has actually doubled in the last ten years.

These figures paint an alarming picture of the state of women's health and make it clear that much work is needed to improve the health of women in many countries.

Antenatal care is an essential safety net for ensuring safe childbirth and healthy mothers and babies. In many countries of the majority world, women lack access to antenatal care simple, basic healthcare services which most New Zealanders take for granted. Emergency obstetric care such as treatment for haemorrhage and caesarean sections is also limited, resulting in a high number of maternal deaths.

One of the reasons for this lack of access to healthcare is the shortage of skilled health workers, whose presence is critical in ensuring the health of mothers and their babies. Assistance by appropriately trained health professionals with proper equipment and referral options in case of complications needs to be available to all women during deliveries if maternal health is to improve.

NZAID is targeting this issue by supporting the Millennium Development Goal 5 on improving maternal health, which aims to reduce maternal mortality by three-quarters and achieve universal access to reproductive health by 2015. The importance of improving healthcare delivery and making primary healthcare services readily available and accessible equally to women and girls and men and boys is also recognised. NZAID's programmes and health policies focus on assistthe capacity of staff at community health facilities and local hospitals - both in terms of the care they provide, but also the information they are able to give.

Another factor in the poor level of health experienced by many women in the majority world is related to sexual and reproductive healthcare. In many countries reproductive health services are limited or poorly utilised. Rates of contraceptive use are low while rates ing countries and communities to develop

of teenage pregnancy and sexually transmitted infections are both high.

NZAID prioritises support to improving access to information and services for reproductive health including contraception, family planning, maternal and child health, and the prevention, treatment and care of women and men affected with HIV.

It is essential to raise awareness that women need these services - both at community level and at a political level. Women and girls need to be in a position to voice their views on health issues that affect them and actively contribute to decision-making processes around health policies at a governmental level.

This will help communities work together to develop their own strategies to address health issues and take steps towards creating an environment where everyone's health needs are met. When women and girls are guaranteed equal access to healthcare - as is their right - whole families, communities and countries benefit.

Melanie Heaphy is communications coordinator at NZAID Nga Hoe Tuputupu-maitawhiti, New Zealand's International Aid and Development Agency.

Addressing issues of maternal health is a focus of NZAID. Photo: NZAID.

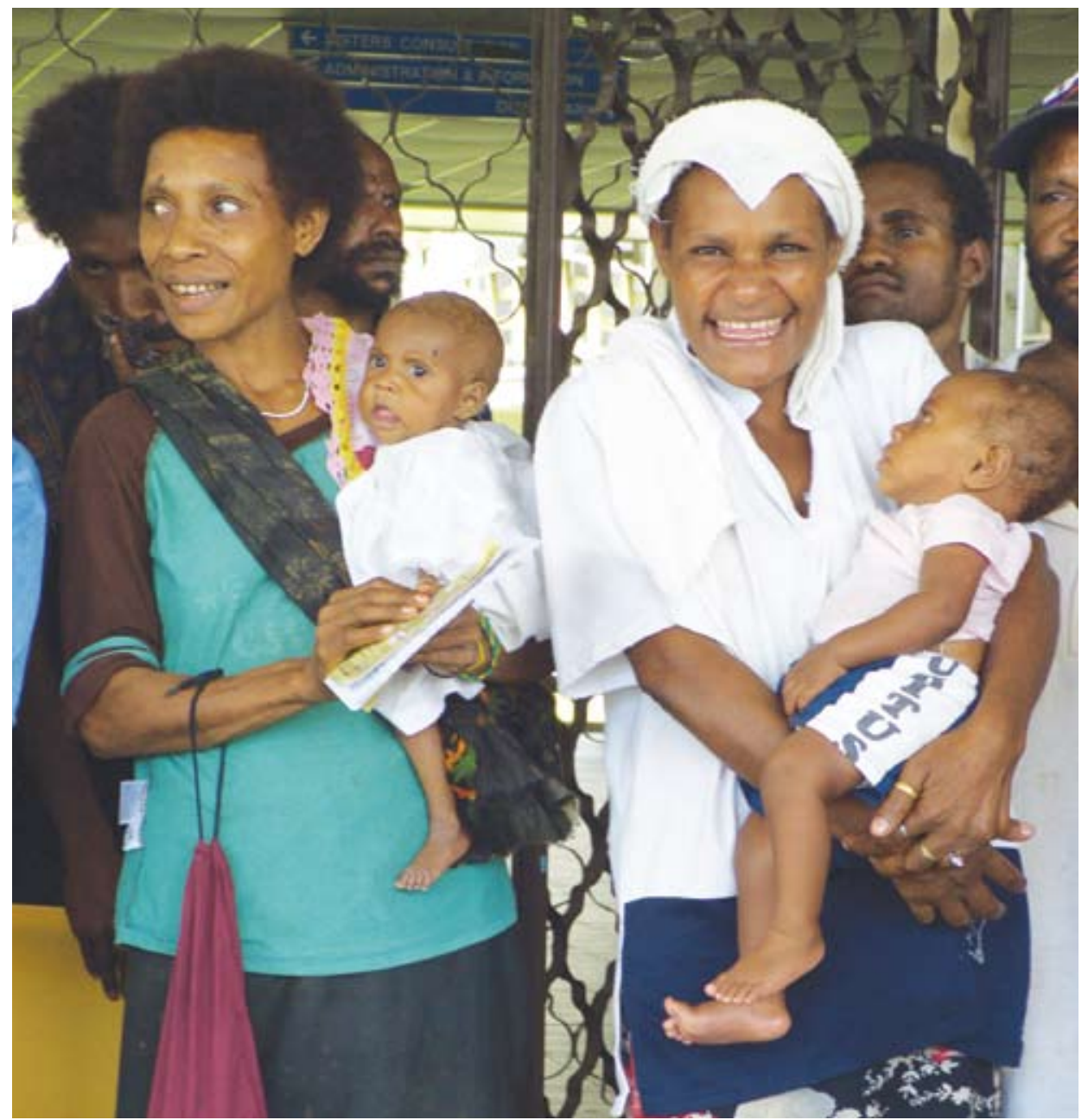




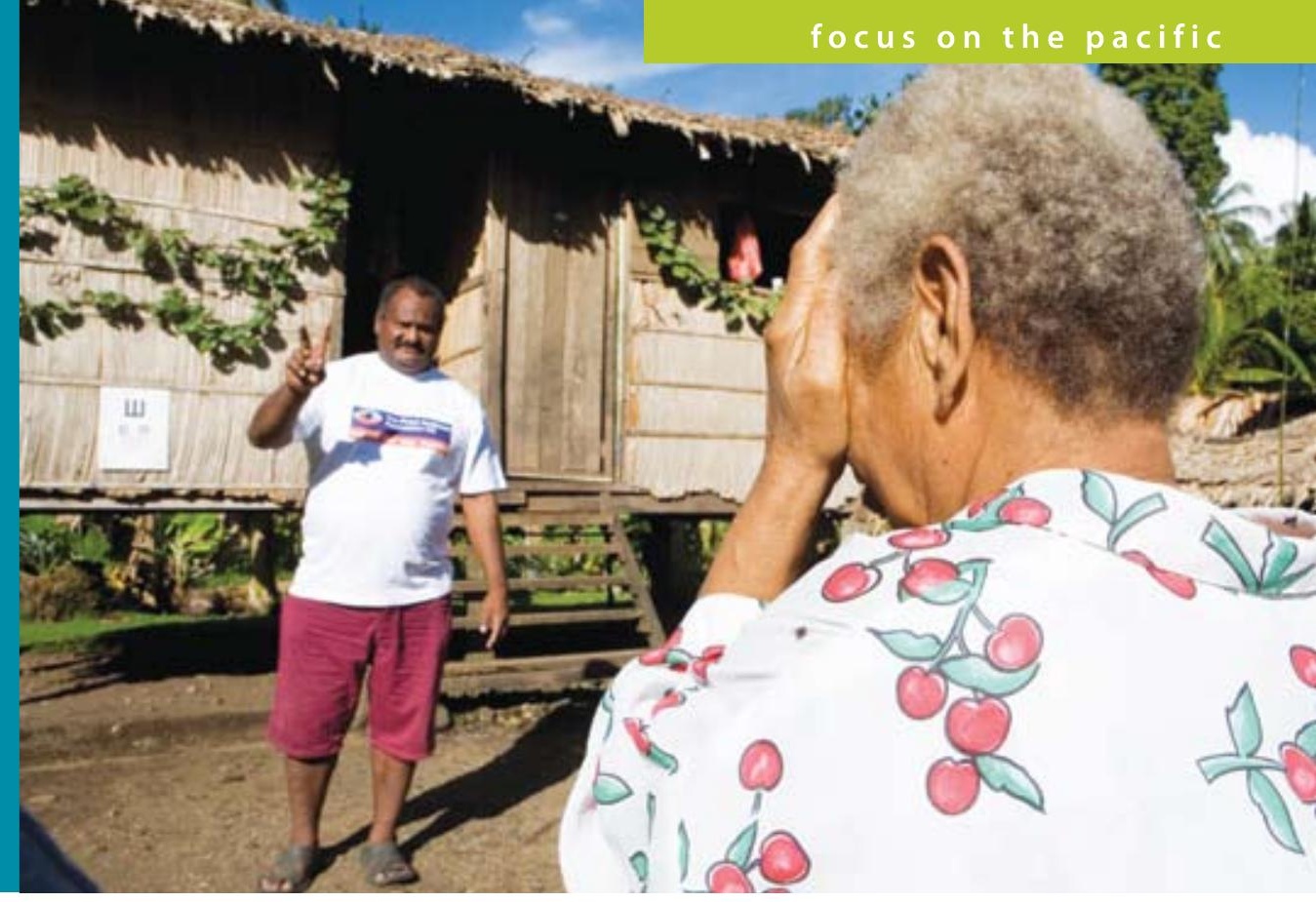

Through a case study of the Pacific Eye Institute, RÈNÉE DU TOIT and JOHN SZETU show that the crucial shortage of healthcare workers in the Pacific cannot simply be solved by training more people.

n most Pacific nations, access to quality healthcare is limited by a continuing shortage of skilled healthcare workers. The public sector indigenous Pacific eye care workforce, for example, mainly responsible for the eye care needs of about nine million people, is comprised of fewer than 15 doctors and 65 nurses. As noted in an article by Williams and Brian, 90 eye doctors and 360 eye nurses are needed to adequately address eye health across the Pacific region. An obvious solution: train more healthcare personnel. Unfortunately it is not that simple.

There are many other factors beyond initial training of health workers that the health sector and supporting NGOs must address to establish a workforce that continues to provide equitable and accessible healthcare. In this article, we draw on our experience in eye health training and workforce development through the Pacific Eye Institute (PEI) to demonstrate

A patient waits to have her bandage removed after sight-restoring surgery by a visiting eye team. During the Fred Hollows Foundation New Zealand surgical outreach visit to Kirakira Hospital in Makira-Ulawa province, Solomon Islands, eye doctors, nurses and trainees saw over 100 patients and restored sight to over 40 people. Photo: Kristian Frires.

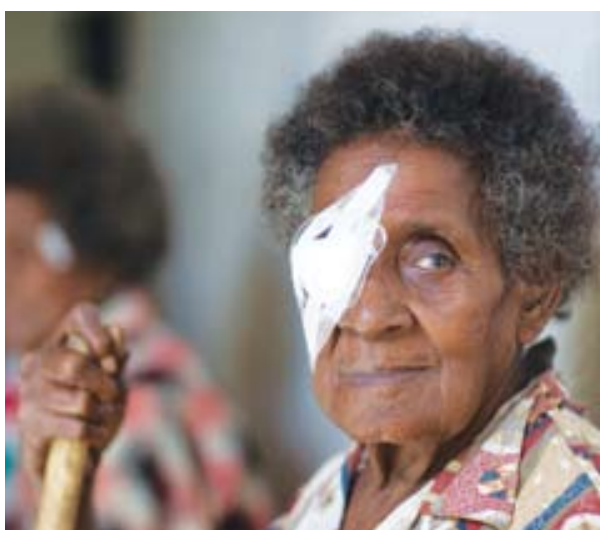

the need to work at many levels to increase access to healthcare for Pacific communities.

PEI is an initiative of The Fred Hollows Foundation New Zealand (FHFNZ). Based in Suva, it was set up as a regional training centre providing specialised postgraduate eye care training for nurses and doctors. Qualifications are conferred by the Fiji School of Medicine. Postgraduate health training programmes can only be sustainable where adequate numbers of general medical and nursing personnel qualify and remain in the Pacific, and where graduates are employed and effectively deployed by the public health sector.

FHFNZ and PEI recognise that a sustainable strategy for training more eye nurses and doctors needs to take place within the context of each Pacific nation's healthcare system. A number of factors are involved here:

\section{RECOGNITION OF QUALIFICATIONS}

Postgraduate qualifications in eye care for both doctors and nurses have been developed in partnership with established Pacific universities and are awarded under their auspices. Widespread recognition for these qualifications assists graduates in achieving career and salary advancement in the Pacific, addressing one of the 'push' factors of attrition.

\section{WORKING WITHIN PACIFIC MINISTRIES OF HEALTH}

Selection of nurses and doctors into the yearlong courses considers their commitment to eye care, as well as that of their employers. The ministries of health must guarantee the graduates' employment in an eye health capacity for a minimum period of one year. The courses train for the regulatory health environment in which the nurses and doctors will work, taking into consideration whether for example, nurses can give injections, prescribe medicines, do minor surgery or sell spectacles.

\section{FOCUS ON MEETING PACIFIC HEALTHCARE NEEDS}

The training is designed to meet local needs by focusing on the main eye problems in the region and offering the courses in circum- stances and with equipment similar to that in the individual's home country. Students gain practical experience at public hospitals and in the community, settings that are consistent with health service delivery in their home countries. It is not sufficient to simply learn clinical skills that cure individual patients. A broader base of competencies, taking a public health approach, forms part of the programmes. These include working as part of a public health team, health promotion and prevention, quality improvement and the use of information and communication technologies. In this way PEI aims to produce graduates with a commitment to professionalism and life-long learning, motivated to provide comprehensive, evidence based care.

\section{ONGOING INVOLVEMENT POST-TRAINING}

After graduation, and when back in their own communities, the eye nurses and doctors then receive technical support, equipment, ongoing mentoring and networking as part of alumni services. Continued participatory evaluation of the performance of eye care providers, and the quality of care they provide, feeds back into PEI's assessment of its courses, and contributes to the plans for ongoing graduate support.

As more eye care personnel graduate and gain work experience, it is hoped that the training workforce will comprise ever increasing numbers of Pacific personnel. It also offers graduates an academic career opportunity which did not previously exist.

In all, much more is required of a training institute in the Pacific health context than clinical or classroom lessons. By addressing training comprehensively, we hope to produce eye health personnel who can provide a sustainable, high quality, accessible eye care service for the people of the Pacific.

Rènée du Toit and John Szetu are from the Pacific Eye Institute, an initiative of the Fred Hollows Foundation NZ. 


\section{The need for young people's voices in the fight against} HIV and AIDS

\section{With HIV infection rates among young}

Pacific people growing, DAVID EPHRAIM argues that young people's efforts to halt the spread of HIV and AIDS need to be recognised and supported.

$\mathbf{Y}$ oung people today are born into a world of HIV and AIDS. In my country, Papua New Guinea (PNG), the World Health Organisation predicts that one in five men, women and children will be infected with HIV within the next decade unless urgent action is taken. With a growing number of HIV infections among young $\mathrm{Pa}$ cific people, youth leadership is vital to drive social change and respond to the pandemic. So why do young people still feel marginalised in donor agencies' and governments' responses to HIV and AIDS?

Millions of dollars and scores of policies, projects, legislation and plans have been pumped into the Pacific region by donors to control the spread of the pandemic. However, HIV and AIDS continues to grow. Despite the potential of development projects to engage and expand youth participation, the reality of participation is not real action, but growing piles of manuals and documents on office shelves throughout the world. In the Pacific, we face a widening gap between adult and youth partnership in different countries. The Global Youth Coalition Against AIDS, created in 2006, has helped strengthen the adult-youth dialogue in some countries, but for others, 'participation' continues to be a concept on paper only. When it comes to putting these manuals into practice, the structural process for youths to access support, funding and technical assistance is often too difficult for both formal and informal youthbased organisations and individuals.

The lack of youth participation has lead to a lack of respect or passion to change amongst young people. Young people today face increasing pressure from changing technology and from their peers. Moral and ethical values are exchanged for the world of technology and entertainment. But HIV and AIDS don't drive much talk at the pubs and clubs; it's all about 'More sex', 'More fun'. 'Get drunk,' 'Get laid'. It's about pleasure.

Yet young people are responding in their own ways to HIV and AIDS.

We take condoms to clubs and try all sorts of strategies to get people to use them. They

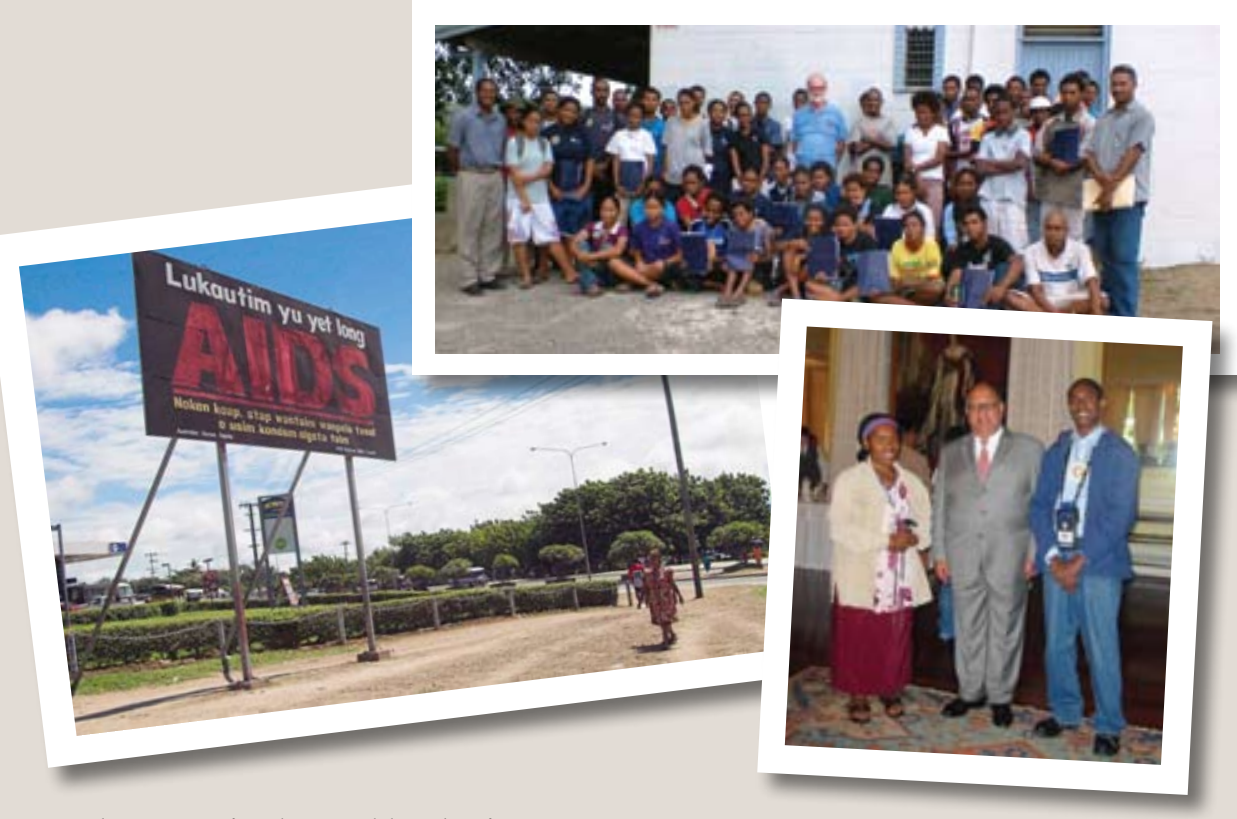

say condoms aren't pleasurable; they're not medically proven to work. So we continue to argue over the promotion and use of condoms. But medically proven or not, it's about giving options to everyone to decide.

We turn to internet-based groups to spread the message. Yet many Pacific countries restrict citizens' access to discussions that aim to raise awareness of vital issues.

So we all go back to the drawing board, hoping things will change; we try to regulate certain behaviors hoping to get some control. We introduce adult-youth partnerships and hope this dialogue will work; we initiate peer education programmes hoping this will

Leadership programmes aimed at empowering and enhancing the capacity of young people must continue to guide our future responses to HIV and AIDS.

work. Does it work? I believe that if you really want to change you can.

But a few days down the line, or after three or four years, funding for these initiatives stops and it all dies out. Why? It costs too much; there's a new management agenda; the project did not meet the donor's requirements.

The rhetoric of youth-adult partnership does not translate into reality. Youth-led responses are not getting the support they need to be sustainable long-term. Even when consultation is included as part of the development process, youths are often excluded. What is needed is for governments to create a working dialogue with their citizens on key issues and
David Ephraim and other members of the Youth Against Corruption Association. Photo: David Ephraim

David Ephraim with the US Ambassador to Papua New Guinea, Leslie Rowe. Photo: David Ephraim.

AIDS billboard outside Lae general hospital in Papua New Guinea. Photo: Asia Pacific Alliance.

create more opportunities for all citizens to be involved in the paths their countries take. If youths are recognised for the important role they play in spreading - or halting - the HIV and AIDS pandemic, we may be able to work together to minimise its impact.

The reality of this pandemic is that it's here to stay and we need to grow up to meet that challenge. Long-term support of young people is vital to drive social change. Leadership programmes aimed at empowering and enhancing the capacity of young people must continue to guide our future responses to HIV and AIDS.

The following statement is from youth at the 8th International Congress on AIDS:

The value of our response has to be recognised as necessary and mainstreamed. We strongly urge you to begin viewing us as equal partners in the response to HIV and AIDS and to move beyond the rhetoric of youth participation by funding youth-led initiatives, engaging in true youth-adult partnerships and meaningfully involving young people in policy that affects our lives.

David Ephraim is the coordinator of Destiny Asia Pacific, an online network of young people working together to establish a stable and peaceful society in the Asia Pacific region. To join, go to: http://asiapasifika.ning.com 


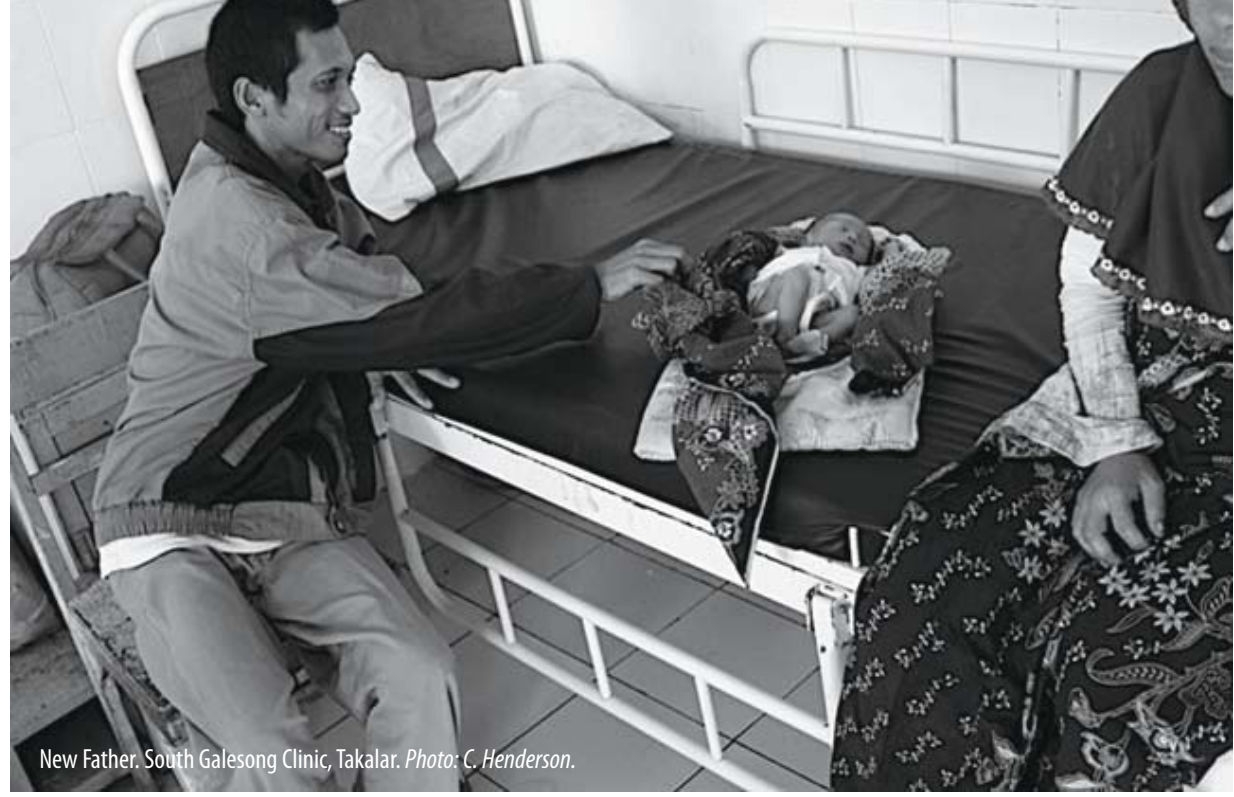

\section{Sipakatau:}

\section{A holistic approach to maternal healthcare}

\section{CHRIS HENDERSON demonstrates how traditional and conventional healthcare can be brought together to build a holistic and accessible approach to maternity care.}

$\mathrm{n}$ the decade before the Millennium Development Goal target for universal access to reproductive health care was set, the World Health Organisation estimated that a skilled health worker attended only $48 \%$ of births in South East Asia. In 2008 this figure has improved to $73 \%$. This, however, does not tell the whole story. Skilled health workers may appear within reach, but economic, geographic and cultural constraints mean access to them is unequal and at the current rate, the 2015 target will remain unmet.

This, until recently, was the situation in Takalar, a district populated by Makassar and Bugis ethnicities in South Sulawesi province, Indonesia. Despite the broad provision and distribution of midwives and birth clinics, $50 \%$ of people still preferred to give birth at home with traditional birth attendants, or sanro, as their primary means of birth support. The sanro harvest much social capital within the community, not only as elders and birth attendants, but also through the many auxiliary tasks they perform. And whilst aptly qualified in massage, preparing and dispensing herbal medicines and as intermediaries with the spirit world, they are underprepared for the management of complications. Conditions such as pre-eclampsia or postpartum haemorrhage, which can be routinely prevented, detected and appropriately managed in a clinic or hospital setting, often result in tragedy at home.

Only when such complications occur are birth clinic midwives belatedly accessed. Their prohibitive fees, youth and different ethno-linguistic backgrounds contribute to this fact and an antagonistic relationship of blame between both parties develops, meaning that the mutual interest of holistic maternal health is lost in the ensuing tension. As many Takalar women attain grand multiparity ( 5 or more viable pregnancies) but do not chose appropriately trained midwifery services, the resulting social cost of maternal mortality is unbearable.

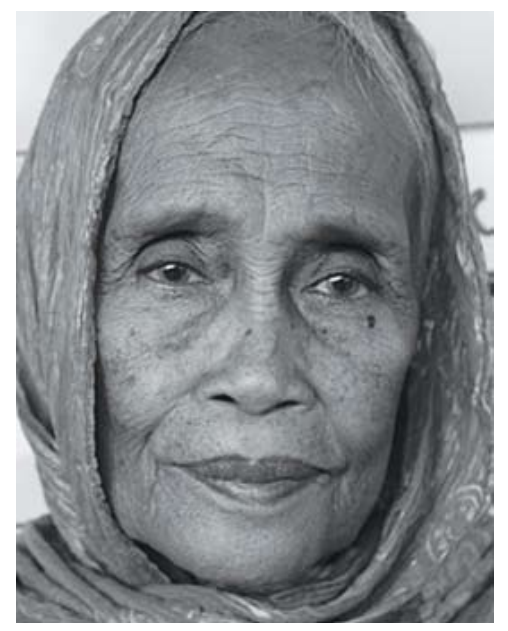

Sanro. Photo: C. Henderson.

According to the International Safe Motherhood Initiative:

more than three quarters of all maternal deaths in [majority world] countries take place during or soon after childbirth, and the single most critical intervention for safe motherhood is to ensure that a health worker with midwifery skills is present at every birth..

Recognising this figure as well as local sociocultural complexities, in early 2007 UNICEF implemented a pilot project to provide universal, free and culturally appropriate access to reproductive health care in Takalar. Coordinated by public health specialist Willy $\mathrm{Ku}$ - murur and social anthropologist Purwanta Iskandar, UNICEF first had to mobilise the local government to fund free birth care and support community actions without instigating seismic socio-cultural shifts at the village level. To achieve this UNICEF worked on advocating for maternal health at every level of a paternalistic political hierarchy; Kumurur regularly met to encourage the king, government officers and imams (Muslim community leader, often head of the mosque), village heads and the heads of households to also push for reform. One wide-reaching product of this advocacy approach is the partnership formed with imams who now employ a maternal health perspective in preaching verses from the Qur'an. Moreover, imams together with village leaders facilitate seminars training husbands how to best provide holistic birth support for their wives, encouraging the use of free clinics and midwives, and how to best facilitate a village fund to provide emergency transport options.

What might serve as the most sustainable approach, however, is the sipakatau-inspired partnership between the government midwives and sanro. Nurman Said writes that sipakatau derives from the Bugis belief that:

every single person is a unique entity in this world and has both rational as well as emotional aptitudes that have to be responded to with full respect.

It is under this pretext that UNICEF brought sanro and midwives together to workshop cultural and professional differences in the interest of protecting women's and newborns' lives. The partnership has since gained endorsement not only from midwives and sanro, but mothers also: 'giving birth now feels complete, I no longer have to bring life into the world filled with fear and uncertainty'. With their rich social capital as a key asset, sanro have taken on a virtual health worker role, referring women to clinics, introducing them to midwives and monitoring consumption of vitamins and medicine, all the while continuing vital psychosocial support in the birth room as a spirit medium, masseur, herbalist and trusted elder. Testament to the success of this partnership is recent data from focus villages describing an access rate to clinic based pre-natal and birth care of over $80 \%$, and the presiding detail that in 2008 maternal mortality has become all but a memory of the past.

Chris Henderson is a Philippines-based advocacy consultant for The Stairway Foundation, and a freelance development researcher. This research was conducted with the support of the Makassar field office for UNICEF Indonesia.Email advocacyeducation@gmail.com for more information. 
It seems there are new reports daily about climate change and its impacts on wildlife, natural resources or displacement of people. In this article, SHERIDAN BARTLETT asks: What about the effects of the changing climate on those who did nothing to cause the problems we face - our children?

$\mathbf{T}$ hree years after Hurricane Katrina hit New Orleans, 20,000 children are said to be still displaced, and between 46,000 and 64,000 children remain at-risk. The poorest and highest-risk families remain in limbo, scattered unmonitored in low-income housing, motels and travel trailers in still devastated communities. Statistics like these are repeated around the world and are set to rise as climate change-related events increase. When extreme weather events hit - including storms, flooding, landslides, heat waves and droughts - children, especially the young, are in many situations those worst affected, both immediately and for years afterward. What's more, almost all the devastating impacts children face are intensified by poverty and the difficult choices low-income households make as they adapt to more challenging conditions.

Food shortages resulting from changes in weather patterns or from interruptions in supplies during acute events, can mean malnourishment for children, increasing vulnerability on every front and can sometimes result in long-term physical and mental stunting. If children are already undernourished, they are less likely to withstand the stress of droughts or extreme events.

Especially where infrastructure is inadequate, heavy and prolonged rains, droughts and conditions after extreme events can all intensify the risk of sanitation related illness. Children under five are especially vulnerable, suffering over $80 \%$ of all diarrhoeal disease. This can lead to higher levels of malnutrition and increased vulnerability to other illnesses, with long term effects for overall development.

Young children, along with the elderly, are at highest risk from heat stress. Warmer average temperatures are also expanding the areas where many tropical diseases can occur, with children most often the victims. The most serious threat is malaria. Up to $50 \%$ of the world's population is now considered to be at risk, and those most likely to succumb are children under five. Malaria increases the severity of other diseases, more than doubling overall mortality rates for young children in affected areas.

The implications go well beyond health and survival. Abundant research relates undernutrition, intestinal parasites, diarrhoeal diseases and malaria, as well as maternal stress and undernutrition during pregnancy, to diminished cognitive capacity in children and lower school performance over the long-term.

Extreme weather events can also have significant psychological costs for children. Although attention is most often given to trauma associated with disaster, frequently it is the deprivations and humiliations of a slow recovery process that children and families themselves report as being the most stressful.

\section{When extreme weather} events hit... children, especially the young, are in many situations those worst affected, both immediately and for years afterward.

Stress and anxiety for parents can translate into family conflict and increased rates of child abuse. Although the tsunami had nothing to do with climate change, it has been the focus of much documentation and research, and it provides a good indication of the risks faced by children in the context of disaster and displacement. For example, the report Battered Islands says that many of the children in India's Andaman and Nicobar Islands who lost parents and loved ones in the 2004 Tsunami still cope with the aftermath. One resident of the islands, a child named Selvi, lost both her parents in the disaster and now lives in South Andaman with her uncle and aunt, who allegedly ill-treat her. The report's authors say that depression and abnormal behavior have become common for Selvi and
These children in Kiribati, like others in the Pacific Islands, face an uncertain future as the impacts of climate change are felt. Photo: Pedram Pernia and Asia Pacific Alliance.

other children affected by the Tsunami.

Life in emergency or transitional housing has been noted in many contexts to lead to an erosion of the social controls that normally regulate behaviour within households and communities. Overcrowding, chaotic conditions, lack of privacy and the collapse of regular routine can contribute to anger, frustration and violence. Adolescent girls, especially, report sexual harassment and abuse. The cumulative effects of such physical and social stress can affect children's development on all fronts. As the numbers of displaced people grow, these dysfunctional environments are likely to become the setting within which more and more children spend their early years.

Although children are disproportionately at risk on many fronts, it is a mistake to think of them only as victims in the face of climate change. With adequate support and protection, children can also be extraordinarily resilient in the face of stresses and shocks. There is ample documentation, moreover, on the benefits of having children and young people active, informed and involved in responding to the challenges in their lives, not only for their own learning and development but also for the energy, resourcefulness and knowledge that they can bring to local issues.

Addressing concerns for children may appear to be an unrealistic burden in the face of so many other compelling priorities. Fortunately, this is not a zero sum game - there are strong synergies between what children need and the adaptations required to reduce or respond to more general risks.

Sheridan Bartlett is a research associate at the Children's Environments Research Group at The Graduate Center, City University of New York, and an associate fellow at the International Institute for Environment and Development in London. 


\section{Development for babies!}

\section{BINDI BORG asks why breastfeeding, which is such an effective health intervention, receives so little funding and consideration in development education and practice.}

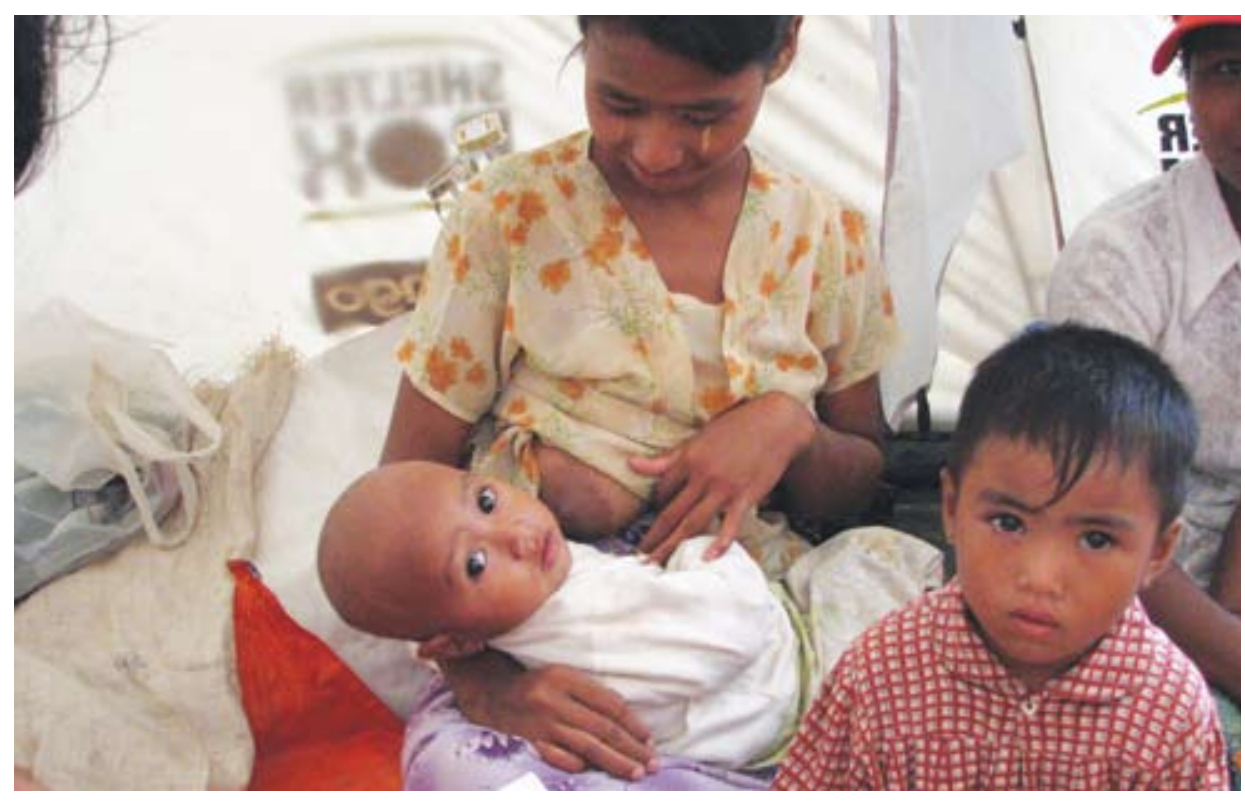

E ach year, UNICEF estimates 1.5 million infants die because they have not been breastfed optimally. Most - but not all - of these deaths are in the majority world. By any standards, this is a serious human rights and development issue. Yet despite the recognition of the importance of breastfeeding, and the well-articulated support for breastfeeding in international law, breastfeeding remains a health and development issue that is poorly understood and receives relatively little attention in development programming.

The World Health Organisation articulated the Global Strategy for Infant and Young Child Feeding in 2003. In the Strategy, optimal breastfeeding entails:

- initiation of breastfeeding within the first hour of birth

- exclusive breastfeeding (no other food or drinks, not even water) for six months

- continued breastfeeding for at least two years then as long as mother and child wish

- introduction of appropriate nutritious indigenous complementary foods with continued breastfeeding after six months.

Breastmilk contains all the nutrients and immune factors that a baby needs until six months, and continues to contribute significantly to children's health beyond six months. Infants that are not breastfed are at least seven times more likely to die from diarrhoea and five times more likely to die from pneumonia than infants that are exclusively breastfed. The Lancet Child Survival Series compared breastfeeding with other preventative health interventions and found it was twice as likely to prevent infant deaths as the next most ef-
A 14-month old feeds in an IDP camp in Labutta, Myanmar, after Cyclone Nargis. Photo: Nina Berry.

fective intervention (insecticide-treated materials). The nutritional and immunological benefits of breastfeeding continue beyond infancy to protect children from communicable diseases (such as diarrhoea and respiratory disease) for as long as they are breastfed and confers protection against non-communicable diseases (such as diabetes and cancers) for a lifetime. Moreover, breastfeeding is important for mothers too, reducing their likelihood of diabetes, breast and ovarian cancer, among others diseases. Thus, breastfeeding is the most effective intervention for infant, child and maternal health. Being fed anything other than breastmilk in the first six months, not continuing breastfeeding for at least two years, or not being breastfed at all, place children and their mothers at serious risk of illness and even death.

A child's right to breastmilk and a mother's right to breastfeed are clearly supported in a number of international human rights instruments. Ultimately, the right to breastmilk protects a child's right to life, particularly in the majority world. UNICEF reports that if every baby were exclusively breastfed from birth to six months, an estimated 3,500 children's lives could be saved each day' The Convention on the Rights of the Child affirms the child's right to 'the highest attainable standard of health'. Children who are not appropriately fed in infancy and early childhood (including exclusive breastfeeding) are unlikely to reach the highest attainable standard of health. In
1981, the World Health Assembly adopted the International Code of Marketing of Breastmilk Substitutes (commonly known as the WHO Code) to ensure the promotion, protection and support of breastfeeding. Ball (2007) and Kent (2001) detail how the Universal Declaration of Human Rights (1948), the International Covenant of Economic, Social and Cultural Rights (1976), the Convention on the Elimination of All Forms of Discrimination Against Women (1981) and various International Labour Organisation conventions support breastfeeding.

If breastfeeding is such an effective intervention in infant health, and is supported by international human rights instruments, why does it receive relatively little attention in development education and practice? Is it because it doesn't cost anything or generate any money on an ongoing basis, meaning no projects with big-sticker funding, no aid that is tied to the purchase of donor country goods and services, and less 'repeat business'? Is it because it's 'women's business', or because it is considered 'natural' and something that mothers and babies should be able to do automatically? Is it because men are less likely to be involved in breastfeeding promotion and protection? There is no doubt that aid is allocated in mysterious ways, but it is perplexing indeed to see that a simple, culturally appropriate intervention that protects the health of women and children and empowers mothers is not enthusiastically embraced by development professionals.

What, then, are the responsibilities of aid and development workers and organisations? At the very least, all aid and development workers, no matter what sector they work in, need to be informed and have a minimum of training in this most basic and fundamental of health and development interventions (see WHO's excellent resources) and to be familiar with best practice infant feeding in emergencies. This basic knowledge can be used to assess how their development programmes - whether in health or other sectors - promote or interfere with breastfeeding. Finally, organisations need to develop and invest in breastfeeding protection and promotion programmes and to build breastfeeding protection and promotion components into their existing programmes.

Bindi Borg is a development practitioner and breastfeeding counsellor/educator with over ten years of experience in West Africa, the Balkans, East Timor, Australia and the Pacific. For more information, email bindi_borg@yahoo.com.au or see the guidelines provided by the Infant Feeding in Emergencies Core Group and the Emergency Nutrition Network www. ennonline.net. 


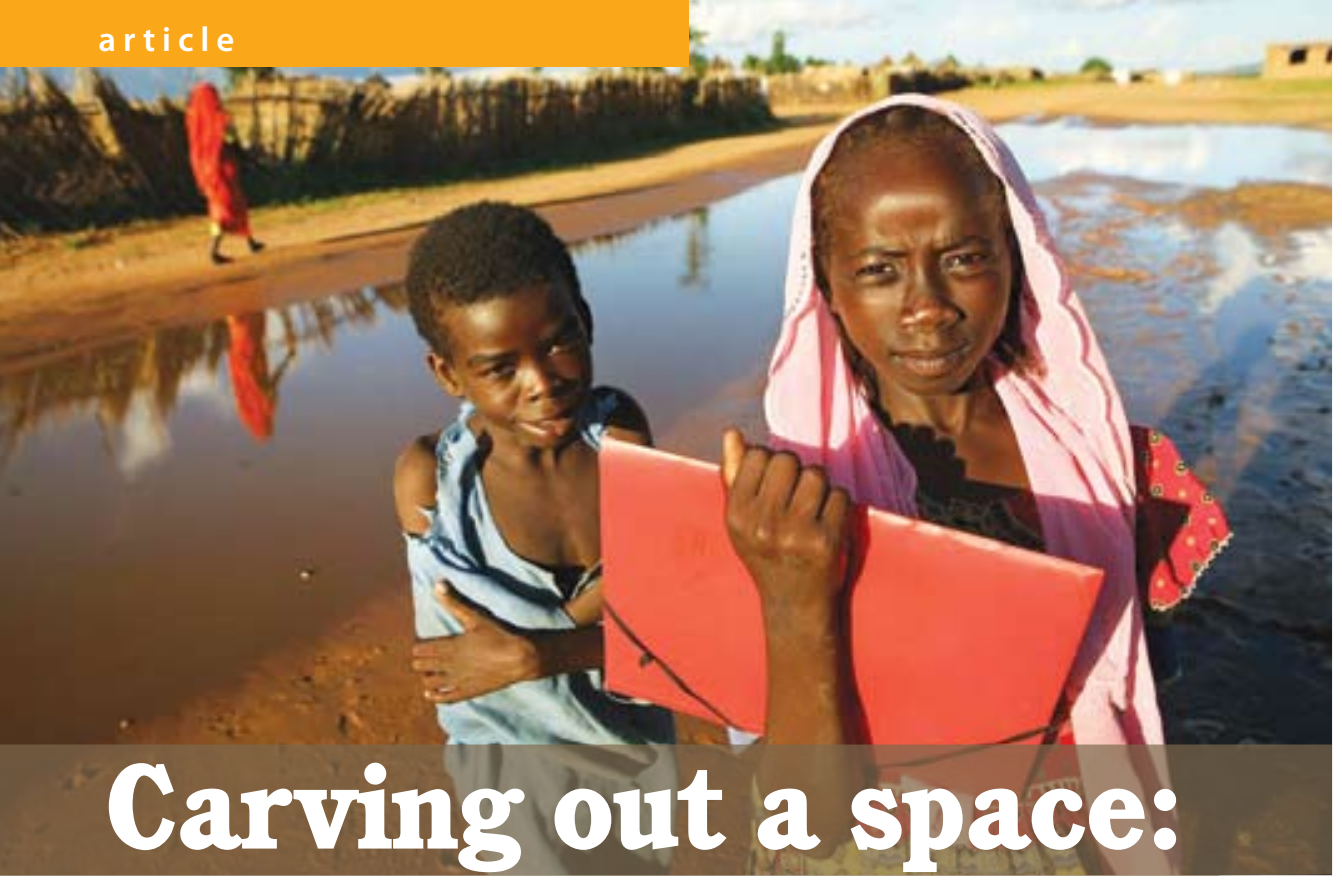

\section{Access to healthcare and aid for Somali and Sudanese refugees}

KARLY CHRIST from Refugee Services argues that for almost $\mathbf{4 2}$ million people around the world uprooted by conflict, making the journey to a refugee camp is not enough to ensure access to healthcare.

$\mathbf{F}$ or the millions of people who have been displaced by violent civil war, oppressive governments and brutal militias, the decision to flee to a neighboring country for refuge is just the beginning of a long journey of survival. Making it to a refugee camp does not mean you will go to bed with a full stomach or have access to much needed healthcare. It does not mean that you are no longer at risk of being raped, beaten or even killed - it just means that your odds are better.

Providing healthcare and basic provisions to war-affected populations is complex in any context, but especially in 'forgotten' areas of the world where wars rage on, ignored by the international community.

\section{HIGH AND LOW PROFILE WARS \\ SUDAN}

Since 2003 the world has watched as the Darfur region of western Sudan endures one of the worst humanitarian crises ever seen. Nearly 2.5 million people have been uprooted due to internal conflict, and the death rate stands at a shocking 200,000-400,000 people.

The extreme violence in Darfur grabbed the attention of the international community and aid money began pouring in from abroad, making it the largest aid effort in the world with nearly NZ\$1.85 billion a year and 14,000 aid workers on the ground. This funding allowed refugees in Chad to be given medial examinations upon arrival and children to be vaccinated. Death rates amongst the displaced were slashed, malnutrition decreased dramatically, and millions were given basic healthcare.
A refugee girl on her way to class in Djabal camp. Early marriages and early pregnancies - some occurring as young as 11 or 12 years old - make getting even a basic education difficult for girls. UNHCR's ninemillion.org campaign aims to provide a healthy and safe learning environment for nine million refugee children by 2010 . Photo: UNHCR/H. Caux.

diseases, alongside appalling sanitary conditions, make healthcare teams hard pressed to deal with the growing chronic needs of this forgotten population.

Violence and insecurity also cripple the limited aid that Somalia receives. Numerous workers have been kidnapped and killed while supply trucks and convoys have been ransacked and robbed, forcing aid agencies to suspend their service delivery. Even with sufficient funding, workers are unable to provide aid on the ground unless there is a relatively safe 'humanitarian space' being maintained.

Unlike in Darfur, where the suffering is being eased by a billion dollar operation, Somalia remains in the shadow of its big neighbour. When it comes to dealing with humanitarian crises, international attention matters. The attention Sudan received, created an environment where donor countries were more forthcoming with funding and resources, giving humanitarian agencies on the ground a more sustainable human and financial resource base from which to improve and maintain healthcare provisions.

\section{A FEW HARD FACTS ON REFUGEES:}

(as taken from UNHCR statistics)

- There are 42 million people uprooted by war - 16 million are refugees and 26 million are Internally Displaced Persons. The former have legal rights under UN international refugee law which places them under UNHCR mandate, but the latter are often just as, if not more vulnerable and in need of assistance.

- Of the 16 million refugees, more than half come from just five countries.

- The average amount of years spent in a refugee camp is 17 , nearly twice as long as it was in 1993.

- In refugee situations the top five killers of children under the age of five are malaria, malnutrition, measles, diarrhoea and respiratory tract infections. All conditions which are preventable and treatable.

- In any refugee population roughly $50 \%$ are women and girls. Females are often particularly vulnerable and have different healthcare requirements, especially with regard to reproductive health.

- Civilians represented fewer than $10 \%$ of trauma victims in WWI and more then $40 \%$ in WWII. Now $90 \%$ of casualties are civilians.

Fate: Somalis in Kenya displaced yet again after Tana River floods their camp. Photo: UNHCR/C.Shirley.

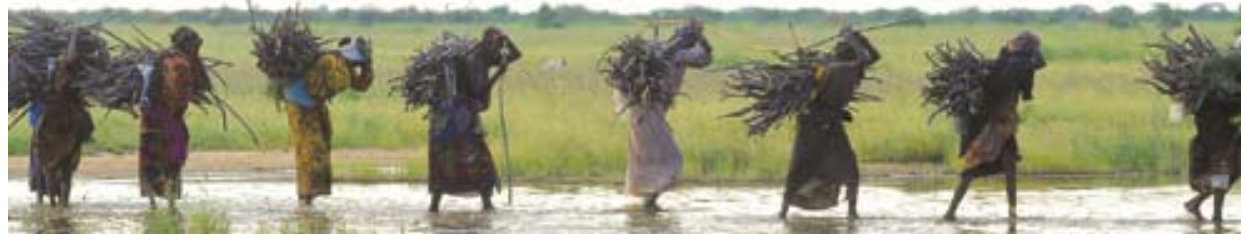


Yet, while Sudan experiences a higher level of commitment in dealing with the humanitarian needs that exists, security issues and lack of government cooperation are proving detrimental to the relief effort. For Somalia, where both of these problems have come to a head - lack of funding and resources, as well as total instability and lack of a humanitarian space - the future of the refugee populations and Internally Displaced Persons looks grim unless things begin to change.

Carving out and maintaining a 'humanitarian space' is critical to delivering healthcare and basic provisions to refugee and displaced pop- ulations. Keeping the international community engaged so that violent corners of the world and the innocent people who call them home are not overlooked ensures that aid money and resources from abroad continue to fuel the humanitarian effort. Without these two scenarios in place, vulnerable people around the world are neglected and forgotten.

Karly Christ has a degree in International Relations from Lewis and Clark College in Portland, Oregon, USA and is currently working as the national fundraising coordinator for Refugee Services Aotearoa New Zealand, www.refugeeservices.org.nz.

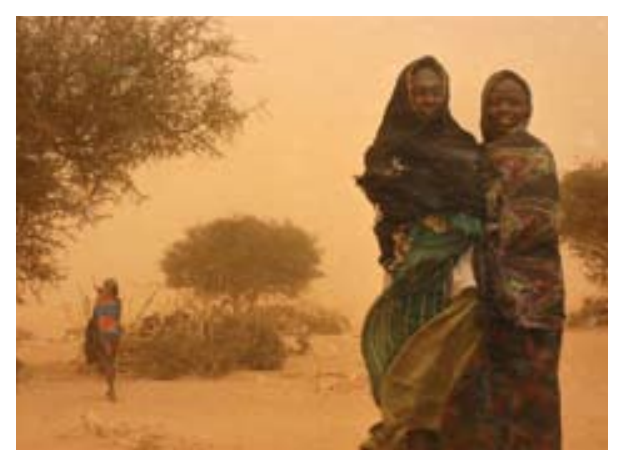

Sudanese refugees caught in a sandstorm in the region of Tine in eastern Chad. UNHCR is relocating refugees from around Tine to Touloum camp, the second camp set up inside Chad. Photo:UNHCR/H.Caux.

\section{Subsidising health care for majority world countries}

\begin{abstract}
The affluence and luxury of the medical and nursing industry in India is not only gaining fame across the globe, it has also popularised a new realm of international trade termed 'medical tourism'. NIKHILA M. VIJAY AND NIRMAL JOY ask what this means for the majority of India's average and low income population.
\end{abstract}

$\mathbf{T}$ he tourism industry is well set to reap the rewards of a new niche market: medical tourism. Its growth stimulated by government policies such as the liberalisation of travel regulations and the privatisation and 'corporatisation' of the healthcare industry, investors have eyed a golden goose. Five-star hospitals are mushrooming around the nation. According to a study by the Confederation of Indian Industry (CII) and McKinsey, medical tourism will bring NZ\$3.73 billion in revenue for Indian hospitals by 2021.

Treatment at India's corporate hospitals costs about one-eighth to one-fifth of that in the US or the UK, with little differentiation made between Indian and foreign patients. It is not surprising that many foreigners are flocking to India to get affordable and highquality healthcare.

However, this success masks many issues that remain unaddressed. Many of the private hospitals in India are registered under the Public Trust Act. They are obliged to provide free service of up to $20 \%$ of their capacity in return for exemption from income tax. Additionally, in recognition of their role in income generation and treating the poor, multi-specialty hospitals receive generous incentives such as free or very cheap land, tax holidays, rebates in customs tariffs and lowinterest loans from public sector banks. However, the government is failing to cross check the accountability of these hospitals, many are not living up to their side of agreements and few poor people are benefiting.

\section{LOCAL PEOPLE'S ACCESS TO HEALTHCARE}

Lack of access to healthcare is exacerbated by the drastic shift of health professionals from the public sector and rural areas to the metropolitan centres where medical tourism is based. Attracted by higher employment prospects, the services of health professionals who once worked in private institutes has become almost exclusively for foreign tourists and Indian elites. While $70 \%$ of the rural population do not have access to proper healthcare for reasons of affordability, the Indian Ministry of Health is accrediting hospitals and recommending prices for their services to guarantee service quality for medical tourism.

Indian private healthcare costs are also likely to rise as the number of medical tourists increases. Even before this tourism boom, healthcare was becoming increasingly expensive. In 1987, the cost of a single treatment in the public health sector in Kerala was $\mathrm{NZ} \$ 0.65$, but this rose to $\mathrm{NZ} \$ 33$ by 2004 . Minority world countries are increasingly concerned about the quality, expertise, and health standards provided (to their residents) in majority world countries. Their governments are thus likely to implement internationally accredited quality systems for hospitals that would result in higher treatment costs. With growing attention given to medical tourism, quality healthcare will probably become unaffordable for the common person.

\section{INDIA AS A DUMP YARD}

Another serious problem is that some corporate hospitals, due to a lack of proper medical waste management facilities, irresponsibly dump their medical waste. Often occurring in populated areas, the local people are given no information about the threats they are being exposed to. In India, a bed in a hospital generates on average $1 \mathrm{~kg}$ of waste per day, out of which $10-15 \%$ is infectious, $5 \%$ hazardous and the rest general waste. To put that in perspective, a big urban corporate hospital generates two million tons of waste each year. Like in many majority world countries, the waste is not separated: from reception-area trash to surgery-room waste, all is burnt in incinerators or dumped into rivers or the sea. These external costs are not included at all in the overall running costs - these businesses appear to be running very cost-efficiently!

\section{NO PAIN BUT GAIN?}

This story peaks in a 'no pain but gain' deal, one that raises ethical questions and clearly shows the influence and buying power of minority word healthcare users. Renting a cheap womb in India to make one's dream of having a child come true is a much cheaper solution than fertility treatment in the minority world. The trade in organs is also a serious problem. Sold, often to pay off debts, an organ goes for an average of NZ\$1820. Despite the $1994 \mathrm{Hu}$ man Organs Transplant Act that criminalised organ sales, inefficient control, corruption and better prices paid abroad mean the illegal trafficking of organs is common. This situation may worsen as medical tourism increases.

Medical tourism is demanding more subsidies and incentives from the government with the argument that it earns high revenues and foreign exchange. Subsidising the corporate sector however, will reduce further the already limited health service resources available to the poor. How could a country like India dare to promote medical tourism when even the basic healthcare needs of the majority of its citizens have not been met? Why should the poor Indian taxpayer pay the price for treatment of medical tourists? What India really needs is to focus on assuring basic healthcare as a right to its own citizens.

Nikhila M. Vijay and Nirmal Joy are active members of KABANI, a collective from India working on tourism issues. They can be contacted at kabanitour@yahoo.com orwww.kabani.org. 


\section{A Case of Neglect? African Sleeping Sickness in Uganda}

\section{JESSICA LEMIEUX assesses progress on the Millennium Development Goals from the perspective of one neglected disease, African Sleeping Sickness. She argues that public private partnerships are needed to overcome the private sector research bias towards minority world diseases.}

n 2000, the G8 developed the Millennium Development Goals (MDGs), designed to reach targets in poverty reduction, gender equity, and education (among others) by 2015. In September 2008, the half-way point, the G8 met again and found that in many countries the goals are unlikely to be met.

Goal Six of the MDGs deals directly with health and addresses the treatment and prevention of HIV and AIDS, malaria and other diseases. Human African Trypanosomiasis (HAT), commonly known as African Sleeping Sickness, is just one of the 'other diseases'.

In Uganda, Sleeping Sickness affects thousands. The disease derives its name from disrupted sleep patterns that develop in later stages of the disease that result in coma then death. Sleeping Sickness is caught by the bite of the Tsetse Fly which is most common in rural areas with cattle or marshlands. Incidences of the disease rises during civil unrest as people are driven into the bush and exposed to flies. This is the current situation in Northern Uganda.

The treatment and prevention of neglected diseases, such as African Sleeping Sickness, has been characterised by a complex array of disappointments, ranging from inadequate infrastructure, research and development biases and expensive patented medicine.

There is a lack of good medication for many of these diseases. For African Sleeping Sickness, the current treatment for its later stages is fatal to one in twenty patients due to its high level of cyanide. Despite the huge innovation potential that exists for many diseases, in the year 2000 eight of eleven large US pharmaceutical companies spent nothing on the neglected tropical diseases found only in the majority world. Before realistic and reliable healthcare can be developed, many factors - especially this access to safe medication - must be addressed.

Preventative measures in Uganda, such as selective spraying were developed and encouraged in the 1950s when surveillance increased due to an outbreak. Selectively spraying cattle in the most bite-prone areas greatly

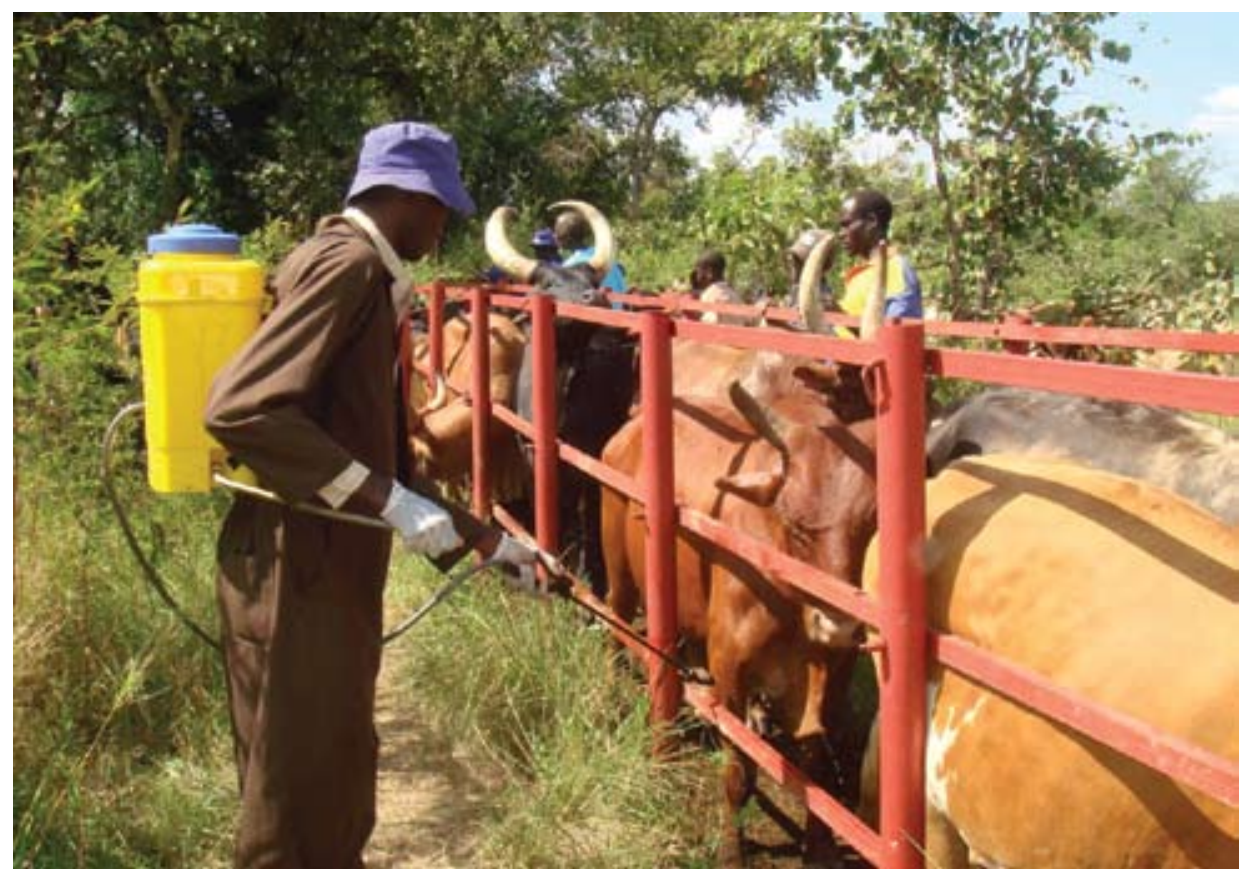

reduces the number of flies. Moreover, it is inexpensive - about four NZ cents per cow per month. Control mechanisms such as selective spraying reduced the number of infected individuals after outbreak. However, surveillance ended when the disease was relatively controlled. Since then the infection rate has increased and has reached almost the same levels as during the 1950s outbreak.

\section{NEW INITIATIVES}

Diagnosis and safer treatment is unlikely to come out of the private sector health industry as there are few who can pay the approximately NZ\$550 treatment cost. New alternatives have been pursued to bridge this gap. New partnerships with non-governmental organisations (NGOs) have, in some cases, proven to be effective. Public-private partnerships have also been successful. Organisations such as 'Drugs for Neglected Diseases Initiative' (DNDi) and partnerships between NGOs (i.e. Doctors Without Borders, Oxfam), the World Health Organisation (WHO), governments and the private sector have created innovative strategies to combat neglected diseases. The fight against Sleeping Sickness in Uganda has benefitted through these partnerships.

New approaches to Sleeping Sickness are primarily connected with Public-Private Partnerships (PPPs) which have had some success in slowing the disease and providing medications. One such partnership is between the WHO and the private company Sanofi-Aventis which supports endemic countries such as
For African Sleeping Sickness, the current treatment for its later stages is fatal to one in twenty patients due to its high level of cyanide.

Uganda and provides free medication. Despite initiatives such as these, there are few clinical trials working to improve treatment. None of these have potential to have a significant effect on treatment or control. DNDi offers hope in its focus on neglected diseases. This organisation, comprised of five governmental and nongovernmental organisations, works to fill in the gaps where fragmented research exists.

Disease in the majority world tends to become neglected when it does not affect the minority world. Alternative approaches, rather than the private health industry, will make a big difference. Fostering these types of partnerships with various organisations may be the way to address diseases that have received little attention. Moreover, preventative measures such as what Uganda received during the Sleeping Sickness outbreak in the 1950s need to be continuous, lowering outbreak numbers while keeping costs low. The MDGs serve as a benchmark towards improving the standard of living for many people. Taking many different approaches to realising these goals, such as public and private initiatives, may make the next G8 meeting more optimistic.

Jessica Lemieux has a BA Honours in Political Science. 


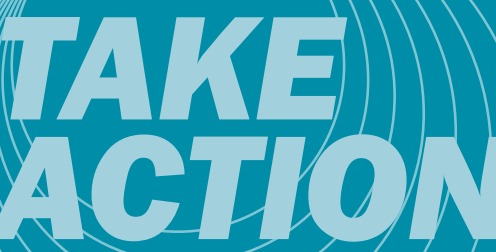

signt the " 6 Mrillion Niore" pledge

Join Oxfam's movement to demand health and education for all.

www.oxfam.org

World AFDS Campaign

The World AIDS Campaign has issue-based and in-country campaigns in support of people living with HIV and AIDS. wwW.worldaidscampaign.org

\section{New Zealand Mental Health Media Grants}

Grants of up to $\$ N Z 12,000$ are available for'developing a media project which can help reduce the incidence of stigma and discrimination for people with experience of mental illness.' www.mentalhealth.org.nz/page/46-MediaGrants

\section{Take Action on Sexual and}

\section{Reproductive Health}

Family Planning International offer a number of ways you can take action on the 'What I can do?' section of their website, including volunteering, fundraising and hosting a speaker event. www.fpi.org.nz

Take a read of Medicine Sans Frontier's Access News-Get Involved edition

This special edition (January 2009) gives you an update on the Access to Essential Medicines campaign and ideas about how you can get involved.

www.msfaccess.org/resources/accessnews/

\section{Get involved in your community's health}

There are volunteer opportunities in many community health initiatives around Aotearoa New Zealand, such as the Red Cross' Breakfast in Schools or Meals on Wheels programmes. www.redcross.org.nz

\section{Ev Letters}

\section{Dear Editors}

I read with interest your last issue of Just Change. I think it is important to really look at energy, how we use it and why we use it if we are ever going to meet the challenge of sustainable energy use. What the articles seemed to highlight for me was how we in Aotearoa New Zealand need to reduce our energy consumption. If this is something that needs to be done, then we need to raise public awareness, not only when water levels are low and we run the risk of power cuts, but a constant effort. This is an important issue and we need major campaigns like the ones we currently have on health issues or drink driving to create the longterm attitude change we need. Public awareness and support are key to not only reducing our own consumption but also in getting the government to pass the tough legislation needed to reduce industry consumption and outputs.
People need to be made aware that science is not going to come up with some magic answer, our whole mindset needs to change. Running a plasma TV or leaving appliances on stand-by is a luxury we don't appreciate, we have to stop taking energy for granted and use it as such.

D. Bryan

Palmerston North

\section{Hi there,}

I thought your magazine was great, a really fantastic contribution and would love to promote them at our events next year

Genevieve

Whangarei

The Just Change Editors welcome your comments and letters. Please send correspondence to justchange@dev-zone.org or Just Change, Dev-Zone, PO Box 12440, Wellington.

\section{Newrs fturom the Development NeW/S itro in ith $(\mathrm{E}$ Resource centre}

In November Dev-Zone manager Maria McMillan went on maternity leave (congratulations on your baby girl, Maria!) and we were lucky enough to have Peter Hardstaff step into her role. Peter previously worked for UK campaigning organisation the World Development Movement. The Dev-Zone events season is in full swing, with information stalls at Parihaka, the Organic River Festival and Pasifika. Look out for us at Wellington's Cuba Street Carnival in February.

The Global Education Centre's Schools team welcomes Ricky Prebble, who is the new secondary schools Education Officer. Look out for the upcoming secondary school resource magazine, Global Issues, which examines environmental challenges facing Pacific Islands. The primary school resource magazine Small World will be out in Term One and looks at Rubbish: from landfill to recycling and everything in between. We also have a new CD-Rom resource on Resistance Movements, featuring Powerpoint slides, curriculum links, and teaching activities.

2009 is shaping up to be an exciting year for the Community and Youth Team with the continuing successes of the Just Write young writers programme and the Global Focus pages in Tearaway youth magazine. In January, nine young writers successfully completed the first intake of the Just Write Certificate. An award ceremony was hosted at Parliament by the Minister of Youth Development, the Hon Paula Bennett. On another note, Global Focus pages, that have appeared quarterly in Tearaway magazine'The Voice of New Zealand Youth' are now a regular monthly part of the magazine. After a successful evaluation, it is clear that global issues are indeed important to young people. 


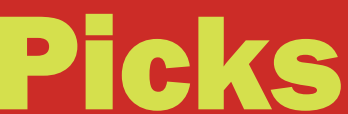

Resources from the

\section{Dev-Zone Library}

He rauemi mai I te kohinga a Dev-Zone

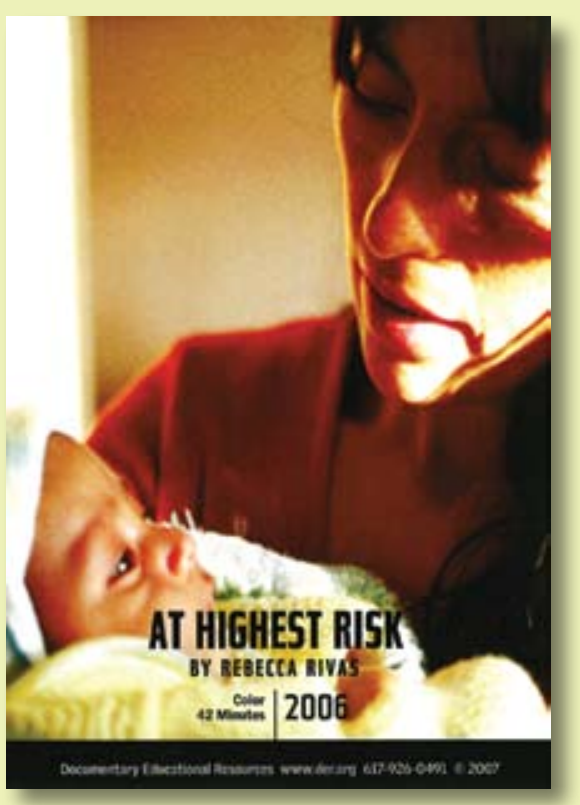

\section{At highest risk}

Watertown, MA: Documentary Educational Resources, 2006. Writer and Producer: Rebecca Rivas, DVD; 42 mins

Within the past decade, the Andean women in Peru have faced the second highest maternal death rate in South America. Yet, the Quechua and Aymara people are fighting to preserve their traditions, beliefs and integrity.

\section{[DVDI:}

\section{Swimming against the tide: \\ The Cuban health system}

United Kingdom: Eureka Cuba, 2008. Director: Tom Fawthrop, DVD; 47 mins

Currently some 30,000 Cuban doctors are providing highquality care in over 70, mainly poor, countries. In Cuba, medical training is provided for would-be doctors from abroad. This film is a timely reminder of what public health is meant to be all about.

\section{Living with Slim: Kids talk about HIV/AIDS \\ Canada: National Film Network, 2004. Director: Sam Kauffmann, DVD; 28 mins}

In many African countries HIV/AIDS is called 'Slim'. In this film, seven African children talk about what it is like to be HIV positive, how they felt when they first learned of their condition, how they are treated at home and at school, and how the illness affects their daily lives.
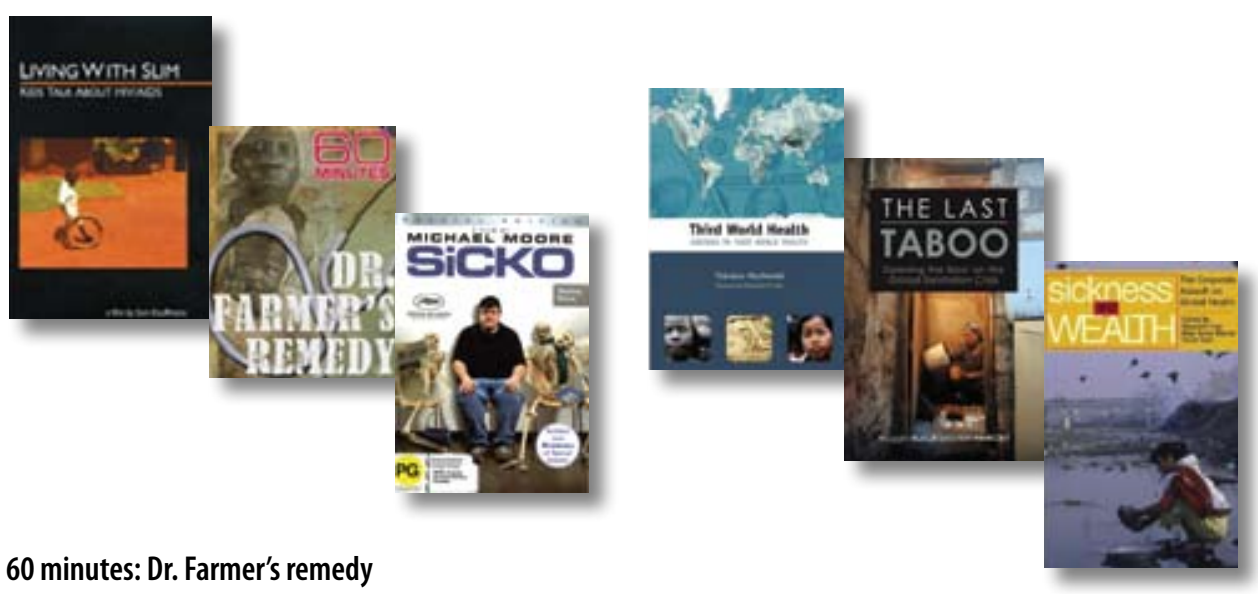

60 minutes: Dr. Farmer's remedy

USA: (BS Broadcasting, 2008. Producer: Catherine Olain, DVD; 12 mins

Twenty-five years ago Dr Paul Farmer found his life's work in Haiti, in one of the poorest parts of the world. Since then, Dr Farmer has dedicated his life to delivering medical care to the impoverished through his organisation, 'Partners in Health', which now works in nine countries.

\section{Sicko}

USA:Dog Eat Dog Films, 2007. Director: Michael Moore, DVD; PAL; 118 mins

Michael Moore returns with this scathing indictment of the United States's failing health system. Combining powerful personal testimonies with shocking statistics, Moore pulls the curtain back on the greedy health maintenance organisations, drug companies and congressmen who keep us ill. Traveling to Canada, England, France and Cuba - where free universal health care is the norm - he forces the question: Why can't this happen in the US?

\section{Bopks}

Third world health: Hostage to first world wealth Theodore L. MacDonald. Oxford: Radcliffe, 2005 Great and increasing health inequalities exist between people both within and between countries; this book argues that countries in the majority world are very much hostage to the globalisation of trade by and for the benefit of minority world countries.

\section{Fixing health systems}

Don de Savigny. Canada: IDRC Books, 2008

Health challenges now confront Africa and the majority world as the effects of devastating epidemics become multiplied by conditions of poverty. In Tanziania, however, recent experience and research are providing a cause for optimism.

Peace through health: How health professionals can work for a less violent world

Neil Arya (ed). Sterling, VA: Kumarian Press, 2008

The idea of working for peace through the health sector has sparked many innovative programmes described in this book by over 30 experts. It covers topics such as prevention and therapy, programme evaluations, medical ethics, activism, medical journals, human rights and the uses of epidemiology.

\section{Case studies in global health: Millions saved} Ruth Levine. Massachuetts: Jones and Bartlett Publishers, 2007 This series of 20 case studies illustrates real-life proven, large-scale success stories in global public health.

\section{Essentials of global health}

Richard Skolnik. Sudbury, MA: Jones \& Bartlett Publishers, 2007 A clear, concise introduction to the most critical issues in global health, illustrating key themes with an extensive set of case studies, examples, and the latest evidence.

\section{The no-nonsense guide to world health}

Shereen Usdin. UK: New Internationalist, 2007

This introduction to the state of health worldwide explores the ways in which health provision is often determined by ethnicity, class and gender.

\section{Gender and health: A global sourcebook}

Anke Van der Kwaak (ed). UK: Oxfam Publishing, 2006

This book presents strategies, approaches, and tools to mainstream gender equity concerns in the formulation of health policy and practice.

\section{The last taboo: Opening the door on the global sanitation crisis}

Maggie Black and Ben Fawcett. UK: UNICEF/Earthscan, 2008 A sanitary reformation is needed today, one that manages to spread cheaper and simpler systems to people everywhere. The authors seek the elimination of the 'Great Distaste'so that people without political clout can claim their right to a dignified and hygienic place to 'go'.

\section{Invisible cure: Africa, the west and the fight against AIDS}

Helen Epstein. New York: Farrar, Straus and Giroux, 2007 This book recounts the struggle of international health experts, governments and ordinary Africans to understand the devastating spread of HIV in Africa.

\section{Sickness and wealth: The corporate assault on global health}

Meredith Fort (ed). USA: South End Press, 2004

This book suggests that global economic and social arrangements are increasingly inegalitarian and could be bad for our health. Militarisation, privatisation, and unfair trade policies are in fact tightly linked to diseases such as malaria, cholera and AIDS.

These are just a few of the resources available from the Dev-Zone Library. Our Library resources are available to borrow free of charge. If you live outside Wellington we will even post them out to you for free! We also have a huge range of magazines, journals and reference material.

You can join Dev-Zone, search the library catalogue and borrow items online at www.dev-zone.org or email us at library@dev-zone.org.

Please see .15 for resources from our online Knowledge Centre. 